\title{
Seismic hazard for the Trans Adriatic Pipeline (TAP). Part 1: probabilistic seismic hazard analysis along the pipeline
}

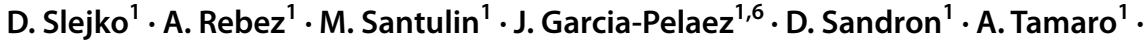 \\ D. Civile ${ }^{1} \cdot$ V. Volpi ${ }^{1} \cdot$ R. Caputo ${ }^{2} \cdot$ S. Ceramicola ${ }^{1} \cdot$ A. Chatzipetros ${ }^{3} \cdot$ S. Daja ${ }^{4} \cdot$ P. Fabris $^{1}$. \\ R. Geletti ${ }^{1}$ - P. Karvelis ${ }^{5}$. L. Moratto ${ }^{1}$. C. Papazachos ${ }^{3} \cdot$ S. Pavlides ${ }^{3}$. D. Rapti ${ }^{2}$. \\ G. Rossi ${ }^{1}$ - A. Saraò ${ }^{1}$ - S. Sboras ${ }^{3}$ - A. Vuan ${ }^{1} \cdot$ M. Zecchin ${ }^{1} \cdot$ F. Zgur ${ }^{1} \cdot$ D. Zuliani ${ }^{1}$
}

Received: 19 September 2020 / Accepted: 20 April 2021 / Published online: 17 May 2021

(C) The Author(s) 2021

\begin{abstract}
The design of critical facilities needs a targeted computation of the expected ground motion levels. The Trans Adriatic Pipeline (TAP) is the pipeline that transports natural gas from the Greek-Turkish border, through Greece and Albania, to Italy. We present here the probabilistic seismic hazard analysis (PSHA) that we performed for this facility, and the deaggregation of the results, aiming to identify the dominant seismic sources for a selected site along the Albanian coast, where one of the two main compressor stations is located. PSHA is based on an articulated logic tree of twenty branches, consisting of two models for source, seismicity, estimation of the maximum magnitude, and ground motion. The area with the highest hazard occurs along the Adriatic coast of Albania (PGA between 0.8 and $0.9 \mathrm{~g}$ on rock for a return period of 2475 years), while strong ground motions are also expected to the north of Thessaloniki, Kavala, in the southern Alexandroupolis area, as well as at the border between Greece and Turkey. The earthquakes contributing most to the hazard of the test site at high and low frequencies $(1$ and $5 \mathrm{~Hz}$ ) and the corresponding design events for the TAP infrastructure have been identified as local quakes with $M_{W} 6.6$ and 6.0, respectively.
\end{abstract}

Keywords Trans-Adriatic Pipeline $\cdot$ PSHA $\cdot$ Ground motion · Deaggregation

D. Slejko

dslejko@inogs.it

1 National Institute of Oceanography and Applied Geophysics - OGS, Trieste, Italy

2 University of Ferrara, Ferrara, Italy

3 Aristotle University of Thessaloniki, Thessaloníki, Greece

4 Faculty of Geology and Mining, Polytechnic University of Tirana, Tirana, Albania

5 Korros-E, Athens, Greece

6 GEM Foundation, Pavia, Italy 
Fig. 1 Basic information about the study region crossed by the TAP: a simplified sketch map showing the plate-tectonic framework of the eastern Mediterranean Sea and surrounding area. The main faults (modified from Aksu et al. 2005) are reported; the blue arrows indicate the relative motions of plates with respect to Eurasia (McClusky et al. 2003); b horizontal GNSS velocities (red arrows) and corresponding error ellipses (red ellipses) modified from Rossi et al. (2020). The TAP route is plotted in green; $\mathbf{c}$ fault plane solutions of earthquakes with $M_{W}>5$ from the global CMT catalogue (www.globalcmt.org) in the 400-km wide buffer zone around the TAP route (in green). For $M_{W}>6.0$ events is reported the date

\section{Introduction}

The Trans Adriatic Pipeline (TAP) is the pipeline that transports natural gas from the Greek-Turkish border, through Greece and Albania, to Italy (TAP AG 2020). The TAP, together with the Trans Anatolian Pipeline (TANAP) and the South Caucasus Pipeline (SCPX), is one of the transport infrastructures of the so-called Southern Gas Corridor, allowing access to the European market for natural gas reserves in the Caspian Sea area (Shah Deniz II Consortium, offshore field south of Baku). By enabling diversification of supply sources, TAP has been one of the projects of most interest to the European Union with a total investment of over $€ 40$ billion.

The pipeline starts at Kipoi in Greece, near the border with Turkey, where it is connected with the TANAP. The total length of the pipeline is about $878 \mathrm{~km}$, most of which in Greece $(550 \mathrm{~km}), 215 \mathrm{~km}$ in Albania, $105 \mathrm{~km}$ offshore in the Adriatic Sea, and about $8 \mathrm{~km}$ in Italy (Fig. 1). The TAP maximum elevation is about $2100 \mathrm{~m}$ above sea level, along the mountain ranges of Albania, while its maximum depth is about $810 \mathrm{~m}$ below sea level in the Adriatic Sea. Along the route, there are four compression stations (two for the initial phase). The pipe diameter is $1.22 \mathrm{~m}$ on the stretch of land with a pressure of 95 bar and $1.07 \mathrm{~m}$ on the stretch of sea with a pressure of 145 bar (TAP AG 2020).

The safety aspects of the pipelines are not covered by specific European regulations (Eurocode 8-Part 4; CEN 2006), mainly focusing on major accident prevention for industrial plants. However, piping systems are not excluded from the same disaster scenarios, in terms of incidence and severity, as those observed for fixed industrial installations. Also, damage to pipelines can cause serious cascading crashes, such as fires and explosions, which pose a significant threat to people and infrastructure near the place of failure. Pipelines buried in earthquake-prone areas may leak or break following a seismic event, especially if the pipeline is affected by permanent ground displacement or strong transient ground jolts (Pyrras and Sextos 2018). Most of the damage reported to date is attributed to peak ground displacement (PGD; O'Rourke and Palmer 1996; Chen et al. 2002), with possible failures triggered by active fault movements (Melissianos et al. 2017), landslides, and liquefaction phenomena (De Risi et al. 2018). Wave propagation effects can also contribute to pipe damage (Sakurai and Takanashi 1969; Esposito et al. 2009; O'Rourke 2009), though to a lesser extent. In fact, ground shaking is not considered a major threat for buried pipelines, except for those sites characterised by the transition between very stiff and very soft soils, locations of pump stations or other critical facilities. For earthquake ground motion assessment, in terms of peak ground acceleration (PGA), peak ground velocity (PGV), and spectral acceleration (SA), a probabilistic seismic hazard analysis (PSHA) is usually adopted (e.g., Mousavi et al. 2014). The more problematic aspect of PGD has been approached in two different ways, either following a deterministic approach based on empirical relationships between the maximum fault displacement and the surface-wave magnitude (Liu et al. 2010) or performing a probabilistic fault displacement hazard analysis (Melissianos et al. 2017). 

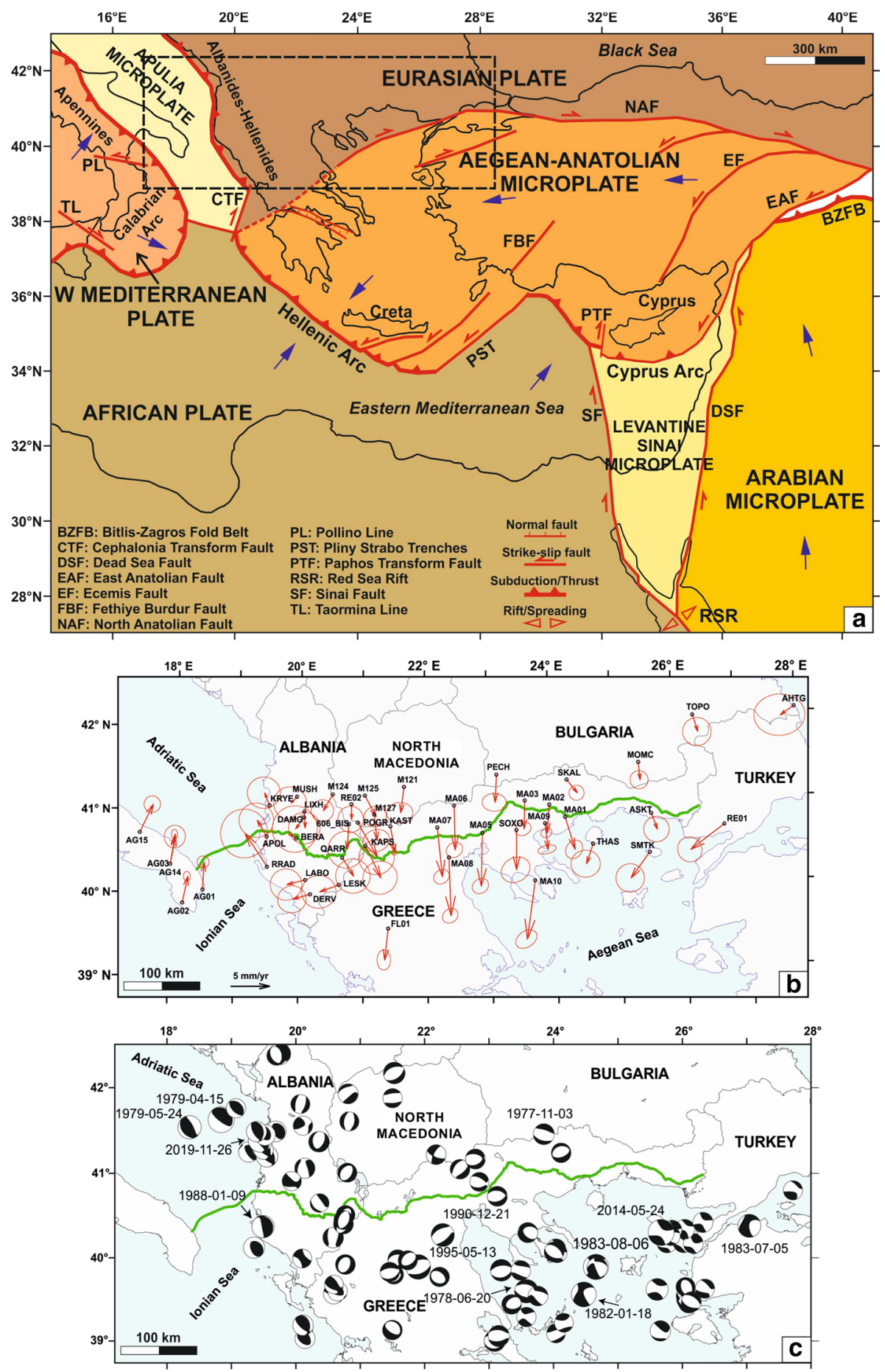
In this context, to assure the long-term safety of the pipeline, it is critical to conduct a study of seismic hazard along the entire route and lifetime of the pipeline. In this paper, we summarise the PSHA done for the TAP. The novelty of this study, with respect to the previously cited studies, is the deep examination of all existing data and the detailed evaluation of the uncertainties involved in the computation. Therefore, a wide range of experts from different disciplines (geology, seismology, geophysics, physics, engineering) was involved in the present study. To account for uncertainties, we applied two approaches for PSHA based on fault characteristics, in addition to the standard approach based on large seismogenic zones (SZs). Seismic hazard based on linear seismic sources (faults) is an innovative approach, although already applied within the European SHARE project (Giardini et al. 2014). It is based on the characterisation of the fault activity, a consolidated topic if well supported by tectonic information. The results based on the fault activity (Sandron et al. 2019) will be of great importance compared to those obtained by the well-known approach based on large SZs, which is here employed as a benchmark for any PSHA.

This study was carried out a few years ago, and some of the ingredients, such as the ground motion models (GMMs), may appear to be outdated. However, we believe this is a case study of broader interest as it is complemented with the results of the deterministic approach (see Moratto et al. 2020 preliminary accepted), and because of its multidisciplinary approach (including geodetic, geophysical, geological surveys).

\section{Geological context}

The geological investigation along the TAP route has been carried out at a regional scale (1:200,000 scale) within a $400-\mathrm{km}$ wide (200 km on both sides) buffer zone along the $878 \mathrm{~km}$ of its extent. The overall aim was to: (1) identify and map the seismogenic sources that could affect the pipeline, (2) provide their seismotectonic parameters. We provide an updated tectonic model of the study area that includes the Italian, Greek, Albanian, and South Adriatic sectors, as well as north-western Turkey, southern Bulgaria, and North Macedonia (Fig. 1). In particular, 163 seismogenic sources have been identified along the pipeline route: 61 in Greece, 30 in Albania, 27 in Bulgaria, 13 in North Macedonia, 1 in Serbia, 2 in Montenegro, 23 in Turkey, and 6 in Italy (Fig. 2).

The TAP route crosses different structural/geodynamic domains, resulting in a strongly variable geotectonic setting that needs to be considered along the main pipeline route. The present-day geological framework of the Mediterranean region results from a series of connected fold-and-thrust belts, associated foreland and back-arc basins of different age, deformation, and internal architecture (e.g., Gueguen et al. 1998; Cavazza and Wezel 2003; Perouse et al. 2012). This configuration is the result of the complex interaction between the Eurasian and African-Arabian continental plates that produced consumption and partial obduction of the oceanic lithosphere of the Tethys region, except for the Ionian basin and the south-eastern Mediterranean. In particular, the tectonic evolution of the eastern Mediterranean has been mainly controlled by (Fig. 1a): (i) the northward subduction (Hellenic subduction) of the African plate along the Hellenic arc beneath western Turkey and the Aegean region, started from at least 100 Myr (e.g., Jolivet and Brun 2010); (ii) the continental collision in eastern Turkey (e.g., Taymaz et al. 2007). The Hellenic subduction produced back-arc extension and volcanism, thinning the continental crust of the overlying Aegean-west Anatolia region (Van Hinsbergen and Schmid 2012; Faccenna et al. 2014; Menant et al. 2016; Papazachos 2019) after the Paleocene compressional phase that formed 


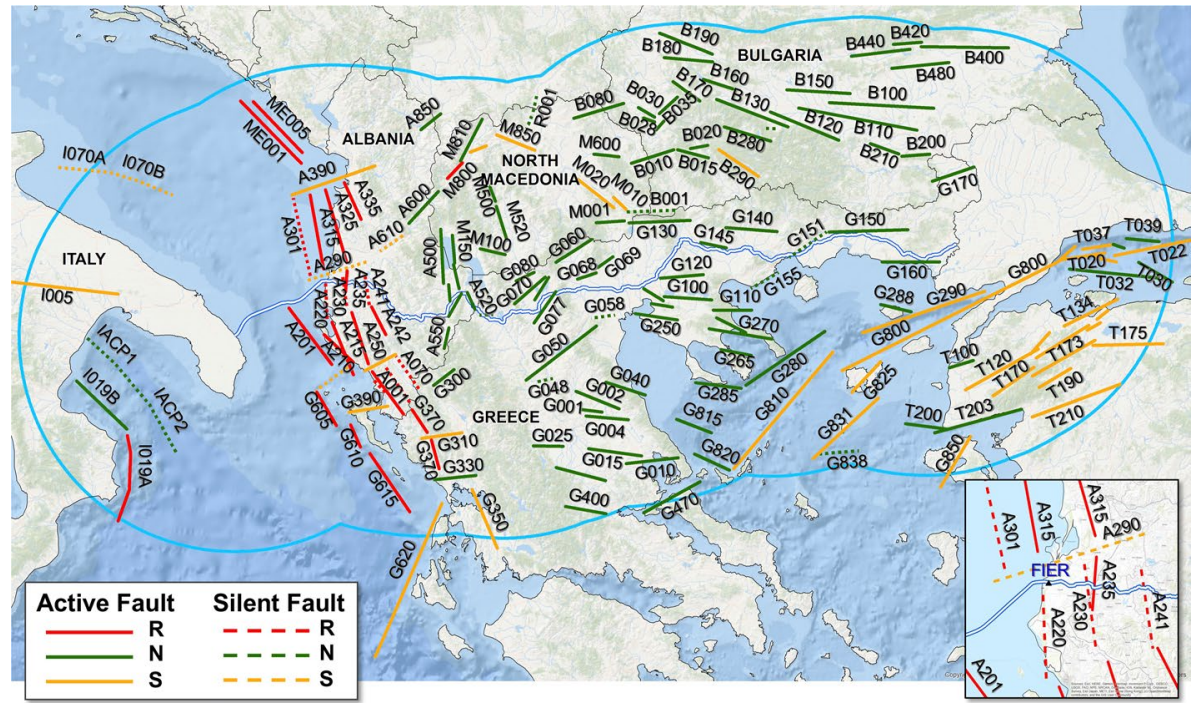

Fig. 2 Simplified fault model representing the top margin of the composite seismogenic sources identified in the $400-\mathrm{km}$ wide buffer zone (cyan line) around the TAP route (double blue line). The labels are the codes of the faults reported in the electronic supplements ES 1 and ES 2. Legend: solid line=active fault, dashed line $=$ silent fault, green line $=$ normal fault, red line $=$ reverse fault, yellow line $=$ strike-slip fault . The inset is an enlargement of the Fier area with the dominant faults

the Dinarides and Hellenides chains (Faccenna et al. 2014). Eastern Turkey suffered crustal shortening and thickening due to the northward motion of the Arabian plate relative to Eurasia (e.g., Taymaz et al. 1990; McClusky et al. 2003; Dilek and Pavlides 2006). GNSS (Global Navigation Satellite System) data show the counter-clockwise rotation of the Aegean-Anatolian plate (Fig. 1b) probably generated by the combination of the slab pull force related to the subduction to the west, and of the pushing from the convergent zone to the east (Taymaz et al. 2007), facilitated by strike-slip movements (Fig. 1c) along the North Anatolian Fault Zone (NAFZ), to the north, and the East Anatolian Fault Zone (EAFZ), to the south (Le Pichon and Kreemer 2010; Nocquet 2012). Presently, African subduction and trench retreat are still active, in particular, the African plate converges at about $0.6 \mathrm{~cm} / \mathrm{yr}$ with Eurasia (Nocquet 2012).

The complexity of the geodynamic framework of the eastern Mediterranean region, including western Turkey and Greece, is reflected in its seismicity. This area is one of the most seismically active and rapidly deforming regions of the world. The seismicity is mostly concentrated along the Hellenic subduction, not included in the study area. Even if the subduction process has no direct influence on the TAP route hazard, part of the tectonics of Greece and Turkey affecting the study area is related to the above mentioned subduction.

\subsection{Italy and the Adriatic sector}

The receiving terminal of the TAP is located in the Salento Peninsula (Apulia) in southern Italy. The Salento Peninsula, together with offshore so-called Apulia swell, constitute the southern tip of the Adria microplate, a carbonate platform sitting on a Mesozoic basement 
(the Apulian foreland) characterised by two opposite-verging Neogene-Quaternary chains: the NE-verging southern Apennines to the west, and the SW-verging Albanides-External Hellenides to the east (Moretti and Royden 1988; Argnani et al. 2001). The Apulian foreland is considered the peripheral bulge produced by the flexural bending due to the loading of the two opposing chains. The southern Apennines are mainly the result of a Neogene deformation that affected the passive Mesozoic palaeomargin of Adria, and consist of a pile of thrust sheets derived from the deformation of Mesozoic-Cenozoic carbonate platform and basin successions detached from their basement (e.g., D’Argenio et al. 1973; Mostardini and Merlini 1986; Casero et al. 1988; Patacca and Scandone 2001) and overthrusted on the Apulian platform during the early Pliocene. Later, the inner part of the Apulian platform was involved in a contractional deformation (buried duplex system) (e.g., Shiner et al. 2004; Patacca and Scandone 2007).

\subsection{Albania}

Albania hosts the Albanides fold-and-thrust belt, which, with the Dinarides to the north and the Hellenides to the south, form a branch of the Alpine orogenic belt. The Albanides are a mainly Neogene chain composed of magmatic and sedimentary rocks from the Ordovician to the Quaternary age that can be subdivided into an eastern internal zone and a western external zone (Robertson and Shallo 2000; Nieuwland et al. 2001; Frasheri et al. 2009; Lacombe et al. 2009). The inner Albanides consist of thick-skinned thrust sheets composed in the Mirdita Zone of Triassic-Jurassic ophiolites and sedimentary deposits, which were involved in the Middle Jurassic to Tertiary tectonism and intense metamorphism. At present, this internal domain is affected by the extension, with direction varying from E-W to N-S (Jouanne et al. 2012). The external Albanides, developed off the passive eastern margin of the Adria plate, are composed by NNW-SSE to NW-SE thrusts, back-thrusts, and folds affected by transfer zones with a NE-SW to nearly E-W orientation (Caputo and Pavlides 2013), such as the Vlora-Elbasani-Dibra (VED) fault zone (Roure et al. 2004) that continues in Macedonia (Dumurdzanov et al. 2005). The external Albanides consist of Mesozoic carbonates and evaporites, and Oligocene to Pliocene-Quaternary clastic deposits.

\subsection{Greece}

The Hellenic orogeny results from the closure of a series of interconnected neo-Tethyan basins and the subsequent collision between Gondwana-derived continental fragments and Eurasia from the Cretaceous to the Oligocene time (e.g., Mountrakis et al. 1983; Mountrakis 2010). Post-Oligocene tectonics was governed by the subduction of Africa beneath the Aegean microplate. The most prominent geodynamic feature of the Aegean region is the Hellenic Arc, consisting of an outer sedimentary arc and an inner volcanic arc (Fig. 1a). The Hellenides are composed of two structural provinces, the external and internal Hellenides, affected by the ophiolitic suture zones of Vardar and Pindos (e.g., Papanikolaou 1997, 2009; Mountrakis 2010; Kilias et al. 2016). The internal Hellenides were characterised by a flyschoid deposition from the Triassic to the Paleogene-Neogene, becoming progressively younger from east to west due to the orogeny migration. A Cenozoic thin-skinned tectonics, characterised by the development of NW-trending thrusts, marks the structural evolution of the external Hellenides (Kilias et al. 2016). The mainland eastern part of the internal Hellenides, which includes southern Bulgaria, mainly consists of 
a Palaeozoic continental crust affected by Alpine metamorphism (Meinhold and Kostopoulos 2013; Kilias et al. 2016). The western portion of the internal Hellenides mainly consists of polymetamorphic imbricated nappes emplaced during the Oligocene, composed of a Palaeozoic or older basement overlain by a Triassic-Jurassic clastic and carbonate succession (Kilias et al. 2016).

\section{Seismogenic sources}

The new seismogenic fault database for the entire TAP, containing all identified active and potentially active composite seismogenic sources (CSSs) in the 400-km wide buffer zone (Fig. 2), was obtained by integrating:

- onshore and offshore geological investigations conducted both on re-elaborated existing geological and geophysical data and new field surveys. In particular, structural data have been collected in some areas of Italy (pipeline receiving terminal zone), Albania, and Greece, while high resolution seismic profiles were acquired by the Statoil (now Equinor) in 2012 along the Adriatic route of TAP and made available for the aim of the project;

- data collected from the databases of seismogenic faults [EDSF-European Database of Seismogenic Faults (Basili et al. 2013), DISS-Database of Individual Seismogenic Sources for Italy (Basili et al. 2008); GreDaSS-Greek Database of Seismogenic Sources (Caputo et al. 2012)]. The sources identified in the cited databases are not actual faults but CSSs (i.e., inferred structures based on regional surface and subsurface geological data that are exploited well beyond the simple identification of active faults or youthful tectonic features) that may contain one or more fault segments and, hence, one or more actual seismogenic sources (Basili et al. 2008, 2013). In the following, the terms fault and CSS are used as equivalents for our purposes;

- literature information.

Following Slejko et al. (2011), we call hereafter "silent faults" the potentially active faults, i.e., the tectonic structures with no clear association with seismicity but showing geological evidence of activity during Late Quaternary and can be, therefore, expected to move within a future time span of concern to society (Wallace 1986). The silent faults (dashed lines in Fig. 2) are applied here for the PSHA because they cannot be neglected, when dealing with a strategic facility [see the safety standards for nuclear installations (IAEA 2010) and Slejko et al. (2011)] and constitute a conservative estimate of the hazard representing the extreme shaking scenarios.

To identify the seismogenic sources (silent faults included) along the pipeline transect in the Adriatic offshore, a combined interpretation of high-resolution swath bathymetric data, high-resolution sub-bottom, and deep seismic profiles were carried out. For the tectonic characterisation of the Italian Adriatic sector, we used the 2D seismic reflection profiles and borehole data made available by the Italian Ministry of Economic Development in the framework of the project "Visibility of Petroleum Exploration Data in Italy" (ViDEPI: www.videpi.com). Consistent geophysical data were unavailable along the Albanian and Greek Adriatic margins, except for part of multichannel seismic lines for the Albania offshore (M-38) and the Greek continental margin (M-34), acquired in 1995 in the framework of the Italian Deep Crust Project (CROP: Finetti 2005). Literature information was used to 
define this sector better (e.g., Finetti and Del Ben 2005; Aliaj 2006; Argnani 2013; Caputo and Pavlides 2013).

The new seismogenic fault database (Fig. 2) has been populated digitally using a GIS database (MapInfo ${ }^{\circledR}$ ), and it includes all the offshore and onshore CSSs identified along the TAP route in the $400-\mathrm{km}$ wide buffer zone around it, and their main seismotectonic parameters. All data referring to the geometry and the activity of the faults illustrated in Fig. 2 are reported in the electronic supplement ES1. The values of the slip rates for the CSSs and their dimensions were computed from geodetic strain-rates (Hollenstein et al. 2006; Pérouse et al. 2012). We interpolated the horizontal strain-rate data considering the region as a continuum and considering individual blocks characterised by a specific tectonic setting, or deformation style (Rossi et al. 2020). The approach considers the fault settings (strike and dip) and the horizontal strain tensor affecting the area containing the seismogenic source. By applying simple trigonometric formulae, the rake is easily calculated. Considering that most of the seismically related deformation occurs within a limited volume surrounding the fault plane, the slip vector can also be obtained by assuming a buffer zone. If the time is included in the calculations (i.e. strain rate values), the slip rates are finally inferred for each fault. Values are reported in the electronic supplement ES2.

\section{PSHA computation}

The seismic hazard of a site is defined as the probability of exceeding a certain level of ground shaking $y$ in a fixed time period. In the probabilistic approach, its calculation is based on the Total Probability Theorem that, in the case of seismic hazard, can be written as:

$$
\lambda_{y}=\sum_{1}^{N_{s}} v_{i} \int_{m_{0}}^{m_{\max }} \int_{r_{\min }}^{r_{\max }} P[Y>y \mid M=m, R=r] f_{M}(m) f_{R}(r) d m d r
$$

where $\lambda_{y}$ is the mean annual rate of exceedance of the ground motion $y ; v_{i}$ is the mean annual rate of occurrence of earthquakes with magnitude larger than, or equal to, $m_{0}$ in the seismogenic source $i ; f_{M}(m)$ and $f_{R}(r)$ are the probability density functions of the magnitude $m$ and distance $r$, respectively; and $N_{S}$ is the number of the seismogenic sources considered in the hazard computation. The above equation represents the seismic hazard curve, in terms of the annual rate (almost equivalent to probability) of exceeding a threshold shaking (McGuire 1995, 2004). The conditional probability $P[Y>y \mid M=m, R=r]$ is simply given by the GMM.

Any distribution can be chosen for both magnitude and distance, as well as for earthquake occurrence. Details about the computation of seismic hazard according to the probabilistic approach can be found in the seminal paper by Cornell (1968), considerations on the pros and cons of application of different distributions and PSHA are extensively described by McGuire (2001, 2004). The quantification of the uncertainties (McGuire 1977) is a well-recognised important point in modern PSHA. Both aleatory variability and epistemic uncertainty (McGuire and Shedlock 1981; Toro et al. 1997) conditionate strongly the hazard estimates, and need proper consideration (Kulkarni et al. 1984; Coppersmith and Youngs 1986). 


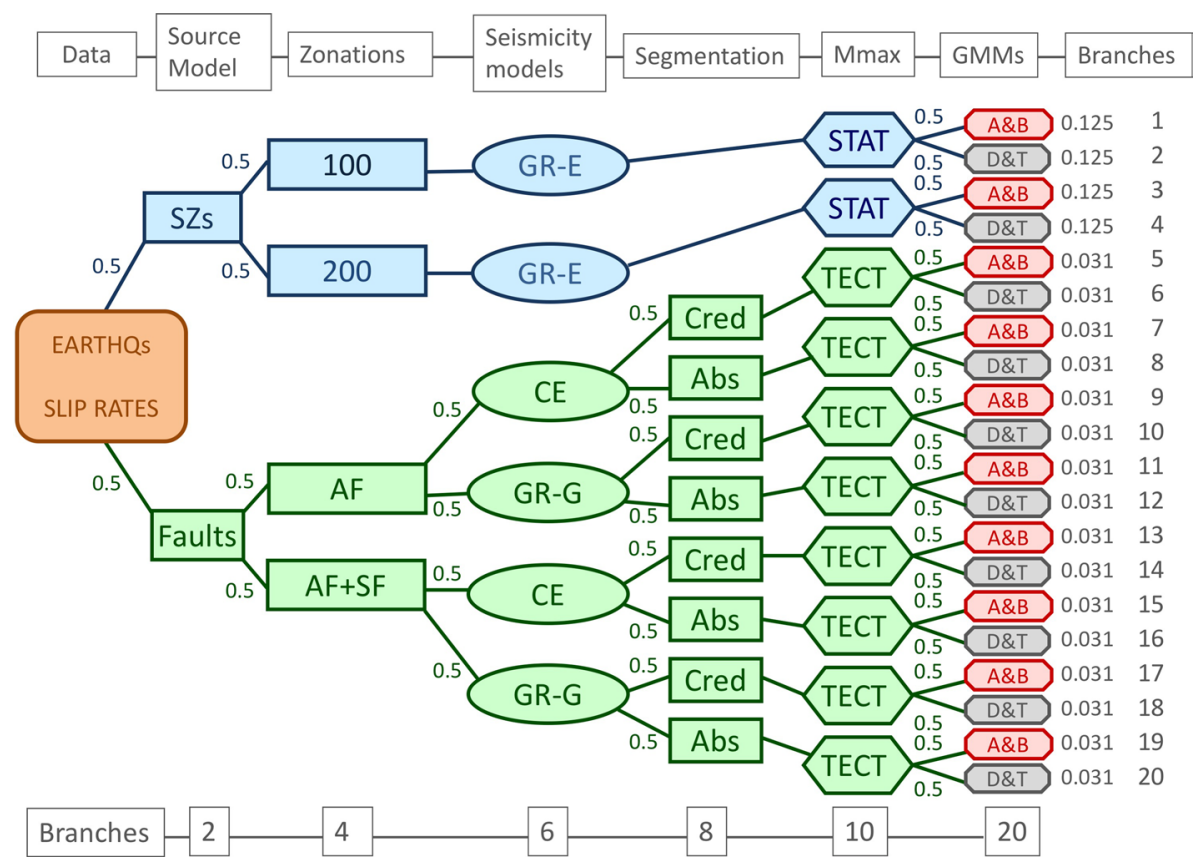

Fig. 3 The logic tree consisting of the two source models: faults and wide SZs. There are two models of faults, the active (AF) and active plus silent $(\mathrm{AF}+\mathrm{SF})$ faults; two zonations (Z100 and Z200) for the model with wide SZs, two seismicity models for the source model based on faults [CE and GR based on slip rates and tectonic features (GR-G)] and only one for that based on SZs [GR based on earthquakes (GR-E)]. In the case of the source model with faults and the CE seismicity model, two rupture areas have been considered: the whole rupture of the fault length (absolute scenario: Abs) and the rupture of only a part of the total length according to a possible segmentation (most credible scenario: Cred). There are two different models [i.e. statistical (STAT) for the SZs and tectonic (TECT) for the faults] for the computation of the maximum magnitude $\left(M_{\max }\right)$, and two GMMs for the ground motion parameters [Akkar and Bommer (2010; A\&B) and Danciu and Tselentis (2007; D\&T)]. Numbers identify the weight of each branch

In the present study, a logic tree (Fig. 3) with twenty branches has been constructed for capturing the epistemic uncertainties. It consists of two source models (faults and wide SZs); two models of faults (only active and active plus silent); two zonations for the model with wide SZs; two seismicity models for the source model based on faults [characteristic earthquake (CE) model and Gutenberg-Richter (GR) model based on slip rates and tectonic features] and only one based on SZs (GR based on earthquakes); two different models (statistical for the SZs and tectonic for the faults) for the computation of the maximum magnitude $\left(M_{\max }\right)$; and two GMMs for the ground motion parameters [Akkar and Bommer (2010; hereafter A\&B) and Danciu and Tselentis (2007; hereafter D\&T)]. For the source model with faults and the CE seismicity model, two rupture areas have been considered: the whole rupture of the fault length, and the rupture according to a possible segmentation. The ground motion parameters considered are PGA, SA for the two spectral ordinates of $0.2 \mathrm{~s}$ (SA0.2) and $1.0 \mathrm{~s}$ (SA1.0), and PGV. Notice that though PSHA is usually performed for bedrock site geology [class A according to CEN (2005)], we have also performed computations for stiff and soft soil conditions, corresponding roughly to B and $\mathrm{C}$ soil classes according to CEN (2005). 
We decided to apply a large suite of models within the TAP project, to take into account all opinions available in the literature, after their detailed evaluation. As we had no way to prefer one choice in the logic tree to another, all branches have been weighted evenly, and the total weight of each branch is reported in Fig. 3.

\subsection{Earthquake catalogue}

The geographical window adopted for the construction of the catalogue is from $38.4^{\circ} \mathrm{N}$ to $43.5^{\circ} \mathrm{N}$ and from $16.0^{\circ} \mathrm{E}$ to $28.5^{\circ} \mathrm{E}$. It is assumed that all the earthquakes that could contribute to the ground shaking along the pipeline corridor have been taken into account.

The compilation of the catalogue followed two phases: the preparation of a data set for the Balkan area (Greece and Albania) and another for Italy and the Ionian Sea. The primary data sources are reported in Table 1 . All the data have been checked (257 events modified) for the period preceding the year 1900 using the SHEEC catalogue (Stucchi et al. 2012), developed in the framework of the European project SHARE (Giardini et al. 2014) and released to the scientific community during the TAP project. Moreover, all Italian entries have been checked (187 events modified) with those of the most recent version of the Italian earthquake catalogue available at that time: i.e., CPT11 (Rovida et al. 2011). Double events have been eliminated following a quality criterion, giving preference to the local information.

The type of magnitude adopted uniformly for the catalogue built for the TAP project (hereafter TAP catalogue) is the moment magnitude $\left(M_{W}\right)$. For several, mainly large magnitude events, original $M_{W}$ estimates were available and published from well-known and calibrated sources (e.g., Pacheco and Sykes 1992, GCMT, USGS, etc.). However, in most cases, the originally reported magnitudes were various local magnitude $\left(M_{L}\right)$ versions, not necessarily computed from Wood-Anderson (WA) instruments but from other shortperiod sensors (Teledyne S13 for most Balkan networks), calibrated against WA $M_{L}$ by each reporting Balkan network. Moreover, for a large number of events other magnitudes (e.g., $M_{S}, m_{b}$, etc.) reported by various sources (e.g., ISC, NEIC, etc.) were available. For all previous magnitudes we have employed appropriate scaling laws converting the original magnitudes to $M_{W}$ (e.g., Papazachos et al. 1997; Baba et al. 2000; Scordilis 2005, 2006; Tsampas 2006; Duni et al. 2010). This "equivalent" $M_{W}$ was estimated as the weighted mean of all available converted $M_{W}$ estimates from other magnitudes, using the inverse standard deviations (SDs) of the conversion relations as weights. Notice that a magnitude conversion was applied only for the range for which each original conversion relation was reported as valid. Using this approach, we also computed a weighted SD for the final $M_{W}$ estimate. While these errors vary, the average SD associated with the final $M_{W}$ of the catalogue (original or "equivalent") is of the order of 0.3 for instrumental locations. For historical events (typically before 1900), when only an estimate of the macroseismic intensity was available, $M_{W}$ has been evaluated using the Papazachos and Papaioannou (1997) macroseismic attenuation relationship proposed for the Balkan region, which also accounts for differences in attenuation among the various Balkan countries. Notice that in this case the typical magnitude SD increases to 0.5 for these historical events.

The TAP catalogue consists of 49,852 earthquakes $(49,149$ of which refer to the Balkan sub-catalogue) with magnitude $M_{W} \geq 3$ from 510 B.C. to 2012. There is a consistent and continuous flow of information for earthquakes with $M_{W} \geq 6$ for the entire historical period, even before 0 A.D. (Fig. 4a); the information is good for events with an $M_{W} \geq 5$ and above since 1500 (Fig. 4b) and for $M_{W} \geq 4$ since 1900, and increases since 1970, with the 


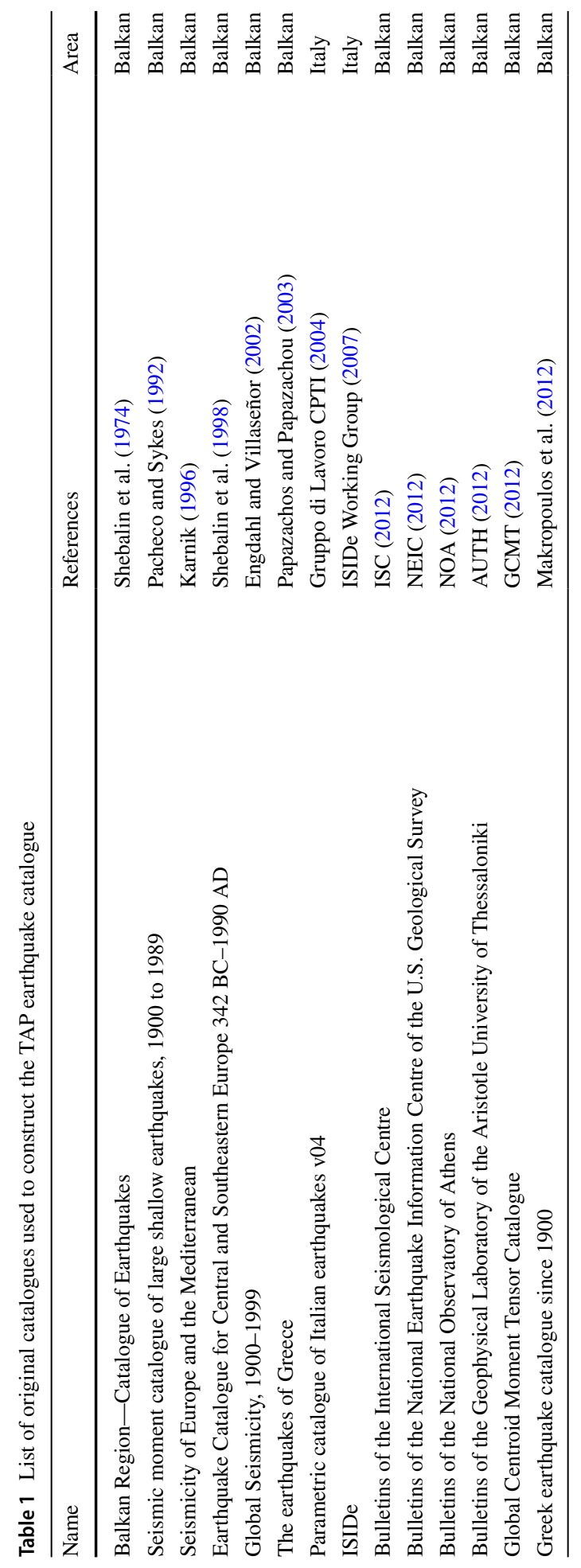



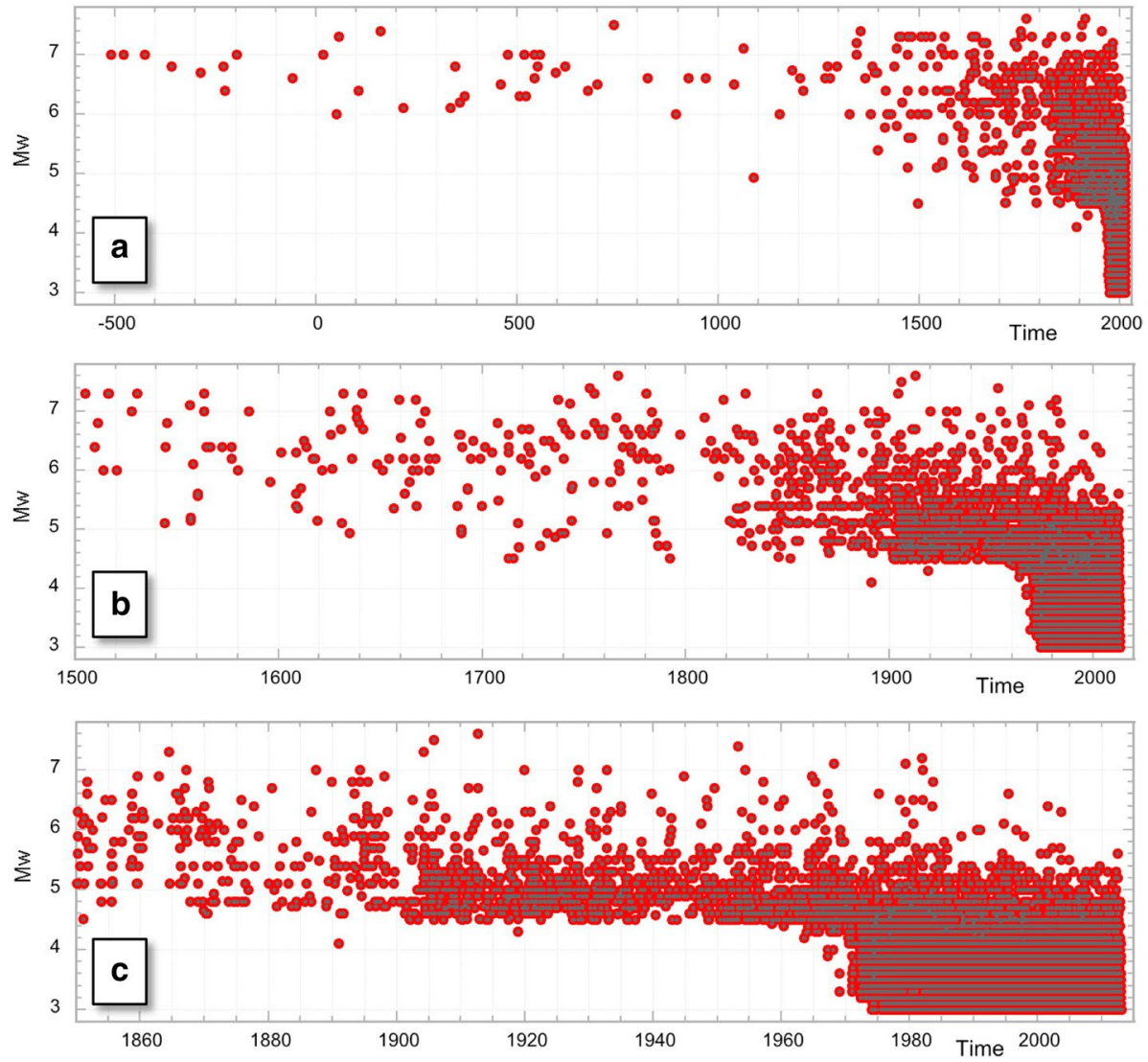

Fig. 4 Distribution of magnitude versus time of the TAP earthquake catalogue for three time periods: a whole catalogue span 500 B.C. to 2012; b period 1500 to 2012; c period 1850 to 2012

appearance of $M_{W} \leq 3.5$ events (see Fig. 4c). Most earthquakes (87\%) have a focal depth within $20 \mathrm{~km}$ and the maximum depth is $60 \mathrm{~km}$.

The seismicity influencing the TAP route is shown in Fig. 5; the buffer region of $200 \mathrm{~km}$ around the pipeline corridor, for which we consider that earthquakes can contribute to the seismic hazard, is also drawn. The TAP crosses the most seismically active area in Albania and only a few earthquakes are reported along the eastern Greek segment of the TAP route, as well as in the Ionian Sea.

According to the Poisson process, we considered only independent events. Consequently, we removed the aftershocks from the TAP earthquake catalogue; more problematic is the removal of foreshocks because no indication is available in the literature, and they are very limited in number, if any. The exclusion of the dependent events was done according to the Gardner and Knopoff (1974) approach: i.e., by applying a space-time window calibrated on the Greek seismic sequences (Latoussakis and Stavrakakis 1992). In such a way, 25,685 dependent events were eliminated from the complete TAP catalogue and the final data file used for hazard estimates (hereafter TAP-DEC catalogue) includes 24,367 events with $M_{W} \geq 3.0$. The declustering algorithm eliminated six earthquakes with an $M_{W} \geq 6$; they are 8 June $1638\left(M_{W} 6.9\right), 12$ February $1743\left(M_{W} 6.6\right), 17$ October 1851 


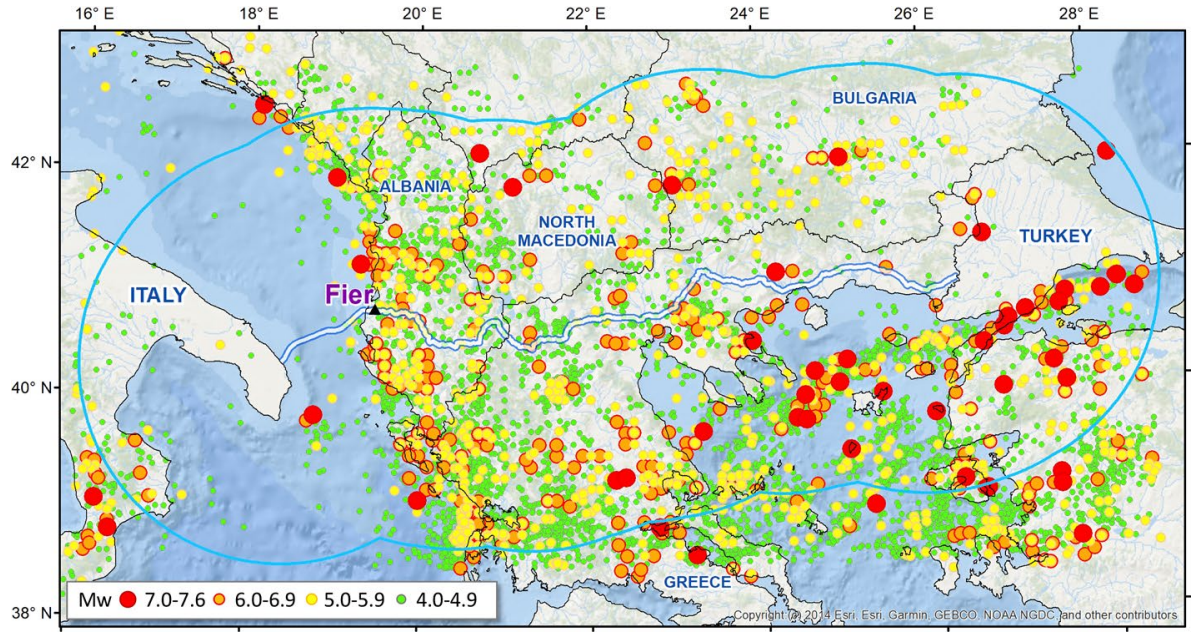

Fig. 5 Epicentres of the earthquakes in the TAP catalogue. The green symbols indicate events with $M_{W} 4.0$ to 4.9 , the yellow symbols $M_{W} 5.0$ to 5.9 , the orange symbols $M_{W} 6.0$ to 6.9 , and the red symbols $M_{W} 7.0$ to 7.6. In double blue line the corridor of the TAP. The cyan line indicates the $400-\mathrm{km}$ wide buffer zone around the TAP corridor

$\left(M_{W} 6.6\right), 13$ September $1912\left(M_{W} 6.7\right), 18$ January $1982\left(M_{W} 7.0\right)$, and 6 August 1983 $\left(M_{W} 6.8\right)$.

An additional assumption requested by the Poisson process is stationarity. Due to the variable population density and reporting, the rates of earthquake activity decrease going back with time. This is a problem due to the catalogue completeness. Only during the last few decades, when regional networks came into operation, the catalogue magnitude of completeness $\left(M_{c}\right)$ has decreased below 3 . Therefore, the catalogue completeness for each magnitude class needs to be evaluated on a regional basis. This has been done separately for Greece and the rest of the Balkan region using the Stepp (1972) graphs (Table 2). Such analysis points out the stationarity of the seismicity by showing the annual rate of earthquake occurrences in time. For Italy and the Adriatic offshore, the $M_{c}$ computed for the whole TAP region has been applied to guarantee a robust regression and the TAP-DEC

Table 2 Completeness periods for the magnitude classes. Route means the whole TAP-DEC catalogue, applied for the offshore sector and Italy

\begin{tabular}{llll}
\hline Magnitude & Route & $\begin{array}{l}\text { Albania and Bul- } \\
\text { garia }\end{array}$ & Greece \\
\hline $7.5-7.9$ & 1310 & 1410 & 1310 \\
$7.0-7.4$ & 1310 & 1410 & 1310 \\
$6.5-6.9$ & 1610 & 1610 & 1410 \\
$6.0-6.4$ & 1660 & 1610 & 1510 \\
$5.5-5.9$ & 1850 & 1860 & 1890 \\
$5.0-5.4$ & 1890 & 1900 & 1900 \\
$4.5-4.9$ & 1950 & 1960 & 1960 \\
$4.0-4.4$ & 1970 & 1970 & 1970 \\
$3.5-3.9$ & 1980 & 1980 & 1980 \\
$3.0-3.4$ & 1980 & 1980 & 1980 \\
\hline
\end{tabular}


earthquake catalogue results complete in a quite long period for large magnitudes $\left(M_{W}>6\right)$, i.e., about four centuries.

\subsection{Source models}

In addition to the linear sources (Fig. 2), identified by the previous geological description, merging the information of the TAP earthquake catalogue (Fig. 5) and the tectonic model, with all available literature about focal mechanisms and stress field, enabled us to define the seismogenic sources, in terms of wide areal SZs (see the complete description in chapter 4.2.2).

For the PSHA along the TAP route, we considered two different approaches in defining the seismogenic sources. The first refers to individual faults, more precisely, CSSs that may contain one or more fault segments, and, hence, one or more actual seismogenic sources (Basili et al. 2008, 2013); the second relates to wide SZs. Silent faults have also been considered in the elaborations related to the model based on faults (see Fig. 2).

\subsubsection{The fault model}

The first source model is linked to the tectonic structures represented by their upper tip in Fig. 2 showing active and potentially active seismogenic sources within the 400-km wide buffer zone along the TAP route. In the present work, we took a precautionary approach considering as active faults the structures showing evidence of displacements during Late Quaternary.

Faults have been classified (and colour coded in Fig. 2) according to kinematics (rake) based on literature information, databases of seismogenic sources as GreDaSS (Caputo et al. 2012), DISS (Basili et al. 2008), and EDSF (Basili et al. 2013), geological and neotectonic maps (see Caputo and Pavlides 2013 and references therein), or it was inferred from the regional stress field obtained from focal mechanisms. Moreover, field studies have carried out collection of structural data where needed in some areas of Italy, Albania, and Greece. In addition, the interpretation of geophysical data was performed to characterise the faults of the offshore part of the TAP route (Adriatic and Ionian seas). The interpreted data set includes 2D multichannel seismic lines, well data, and technical reports related to the hydrocarbon exploration made available in the framework of the ViDEPI project, MS-29 and CROP M-34 seismic lines, high-resolution profiles of the Statoil TAP survey data set acquired in 2012 along the Adriatic route of the pipeline.

Special mention deserves the source of the $M_{W} 7.120$ February 1743 earthquake, which was widely felt, with damages, in the Salento peninsula (Apulia) and Ionian islands. The earthquake was perceived by the majority of the witnesses as a sequence of three violent shocks and this may be the result of the activation of different fault segments. The epicentre of this event is quite uncertain, and its location reported in Italian [offshore the Salento peninsula (Rovida et al. 2011)] and Greek [south of Corfu island (Papazachos and Papazachou 2003)] catalogues differ notably. Although different faults have been proposed for this earthquake (Argnani et al. 2001; Galli and Naso 2008; Milia et al. 2017; Maesano et al. 2020), the source remains poorly constrained: we considered the source proposed in the DISS (Basili et al. 2008) and the AHEAD (European Archive of Historical Earthquake Data, www.emidius.eu/AHEAD) databases, also supported by additional considerations by Argnani et al. (2001), in the Otranto channel, where some small magnitude events were located instrumentally (D’Ingeo et al. 1980; Gasparini et al. 1985; Favali et al. 1990). As 
we are not able to model a 3D geometry for this source, we represented it as a horizontal 20-km deep polygon, whose top does not intersect the surface, in agreement with the Argnani et al. (2001) interpretation confirmed also by the recent data and interpretation of Maesano et al. (2020). This geometry could also justify the wide perceptibility area of the 1743 earthquake.

\subsubsection{The wide SZ model}

The choice to consider SZs, wide or narrow according to the available seismotectonic information, is motivated by the difficulty of associating specific earthquakes with individual faults, due to the uncertainties in the earthquake location and the poor knowledge of the geometry of the faults at depths. To delineate seismogenic sources, an adequate kinematic model is essential, capable of explaining the Quaternary evolution of the whole area and describing the current movements linked to the seismicity. The seismotectonic model of the TAP offshore region was approached by extending the kinematic and seismotectonic analyses of the Adria microplate (Slejko et al. 1999). The Adriatic region is interpreted as a rigid microplate bordered on the eastern, northern, and western margins by deforming mountain belts, including the Albanides, the Dinarides, the Southern Alps, and the Apennines. The southern margin of the plate, i.e., the Africa-Adria boundary, is still undefined. Transversal tectonic structures to the chains, which interrupt the continuity of the mountain belts, are interpreted as shear zones. They separate sectors of the chain affected by different deformation age, distinct structural trend and tectonic evolution. The Cephalonia transform fault zone represents the most evident shear zone. Other regional structures are the VED transversal fault zone, which affects the central part of the Ionian-Adriatic thrust fault zone (Albanides), and the Scutari-Pec (SP) fault that marks the boundary between the external Dinarides and Albanides (Aliaj 1998).

The seismogenic model proposed for the TAP route $(400-\mathrm{km}$ wide from the TAP route itself) is, then, based on all available geological literature (Aliaj 1998, 1999, 2000; Velaj et al. 1999; Robertson and Shallo 2000; Nieuwland et al. 2001; Zelilidis et al.; 2003; Roure et al. 2004; Frasheri et al. 2009; Lacombe et al. 2009; Vilasi et al. 2009; Silo et al. 2010; Jardin et al. 2011; Jouanne et al. 2012), on earthquakes distribution (Fig. 5), and previous proposed seismogenic zonation for Albania (Aliaj et al. 2000, 2004; Aliaj 2002; Sulstarova and Aliaj 2001), for Greece (Papaioannou and Papazachos 2000; SEAHELLARC Working Group 2010, 2014; Vamvakaris et al. 2016), for Bulgaria (Orozova-Stanishkova and Slejko 1994; Simeonova et al. 2006), for North Macedonia (Salic et al. 2010), and Italy (Meletti et al. 2008).

The model based on wide SZs has two variants (zonations): with transfer zones along the Albanian coast (hereafter Z100, see Fig. 6a) and without them (hereafter Z200, see Fig. 6b). According to the logic tree approach, the different branches should be mutually exclusive and collectively exhaustive, although this requirement is often not formally satisfied in the literature. In our case, the kinematic model for the coastal area (Slejko et al. 1999), which is the most important sector for the TAP route due to its high seismic activity, suggests two alternative kinds of activity for some tectonic structures. Then, our two zonations reflect this primary aspect, whereas for the SZS in the remaining study area we did not identify relevant differences (Slejko et al. 2014).

More precisely, Z100 (Fig. 6a) takes into account three shear zones as actual seismogenic sources: the SP (modelled as SZ 173 in Fig. 6a) in the north, the VED (modelled as SZs 176 and 177) in the central part of Albania, and the Othoni Island-Dhermi Pass 

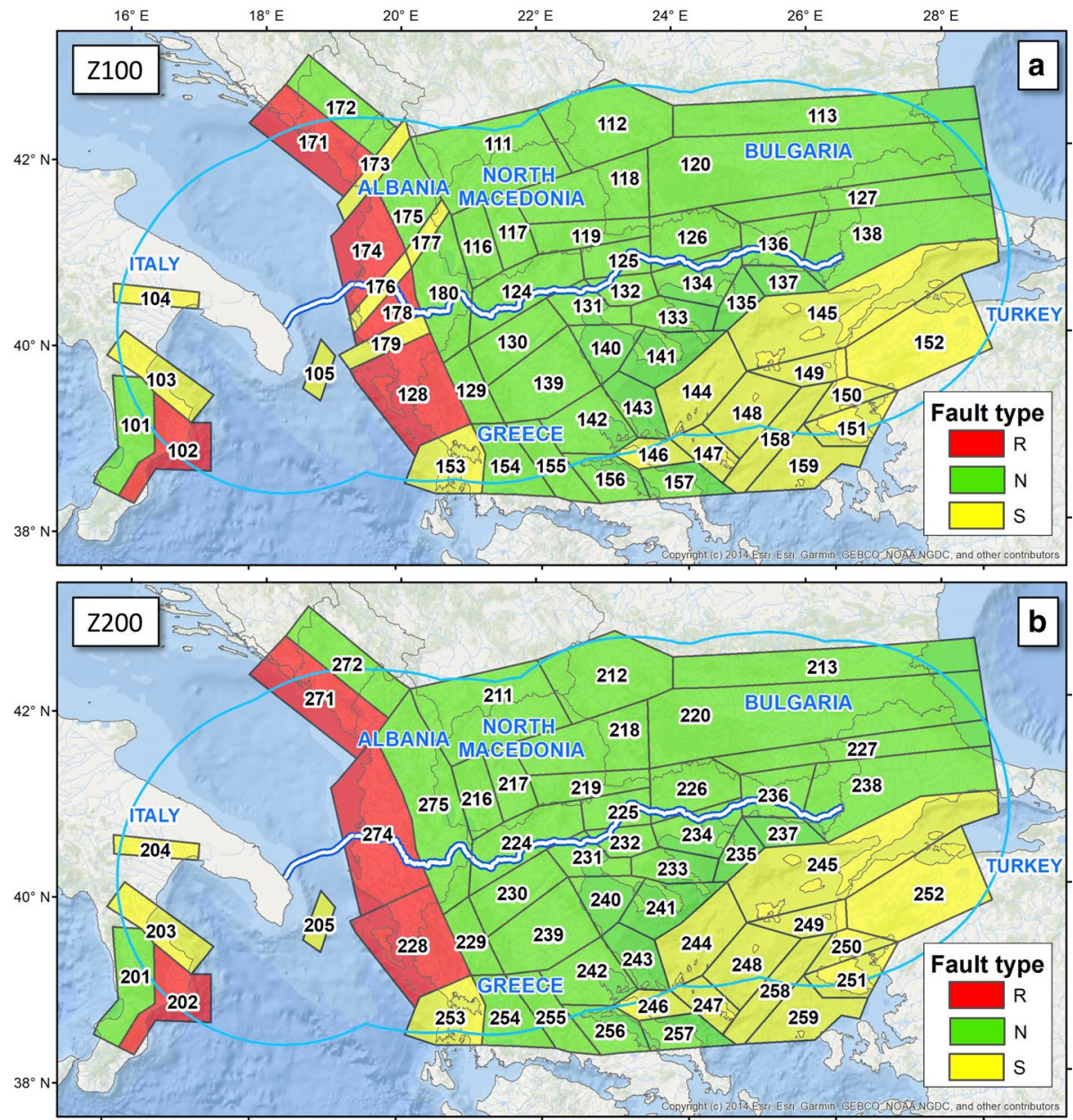

Fig. 6 Seismogenic zonations for the TAP route: a Z100 that considers the transfer zones in Albania (nos. 173, 176, 179); b Z200 without them. The cyan line indicates the 400-km wide buffer around the pipeline route (double blue line). The colour indicates the kinematic character of the zone: green $=$ normal, red $=$ reverse, yellow $=$ strike-slip

(modelled as SZ 179) in southernmost Albania. The subdivision of the VED transversal zone into two parts is motivated by the different kinematics that it exhibits: pure strikeslip movement in the south-western sector, and transtensive kinematics in the north-eastern one. Also, geodetic information supports the adopted separation (Rossi et al. 2020). Another important tectonic structure affecting the external Albanides is the ENE-trending Othoni Island-Dhërmi Pass (OD) right-lateral strike-slip fault (SZ 179), located to the south of the Karaburun Peninsula, which is characterised by earthquakes with an $M_{W}$ greater than 6. This lineament is considered the most active fault of Albania (Jouanne et al. 2012). The VED transversal zone and the OD fault divide the Ionian-Adriatic thrust fault zone into three segments (SZs 174, 178, and 128). In particular, the northern (SZ 174) and southern (SZ 128, including the offshore Corfu thrust and the contractional structures of the Saranda area) zones comprise both onshore and offshore contractional structures, 
characterised by earthquakes with an $M_{W}$ greater than 7 . SZ 153 corresponds to the northern part of the Cephalonia seismogenic tectonic lineament: only this sector has been considered because the southern part is too far away from the TAP route and does not contribute to the expected ground motion.

The seismogenic model for broader Greece (Pavlides et al. 2010; Caputo et al. 2012; Vamvakaris et al. 2016) has been fully adopted with very minor changes along its peripheral margins to take into proper consideration also the national seismogenic models proposed for Bulgaria (Simeonova et al. 2006). In particular, as these areas are quite far from the TAP route and can contribute very marginally to the expected ground motion, fewer details have been incorporated to allow a conservative distribution of the seismicity.

The SZs defined in Italy are taken from the seismogenic zonation used to compute the Italian seismic hazard map (Stucchi et al. 2011) with some modifications. More specifically, SZ 102 has been enlarged towards the sea, according to recent literature (Zecchin et al. 2018; Mangano et al. 2020). SZ 103 has been introduced because a few earthquakes close to magnitude 6 affected the tectonic structure of Pollino, in southern Italy.

The second zonation (Z200, see Fig. 6b) considers the transversal shear zones only as borders of the seismogenic zones affected by thrust tectonics.

The SZs in the peri-Adriatic region, shaped according to seismicity data too, represent the surface projection of the active fault systems capable of producing earthquakes characterised by similar mechanisms. Considering the fault type inside each SZ as previously described (Fig. 2), it was possible to define a dominating character (normal, reverse, transcurrent) for each SZ of Z100 (Fig. 6a) and Z200 (Fig. 6b).

All the SZs of the two zonations have been modelled as flat surficial planes.

\subsection{Seismicity models}

For the wide SZs the seismicity is generally characterised using the GR model (GR-E in Fig. 3). For individual faults the related seismicity model is difficult to define and questionable (e.g., Wesnousky 1994), because of the hypocentre location errors and because of the poor knowledge of the fault deep geometry. Therefore, we decided to consider two possible seismicity models for the faults: the GR model fed by geodetic data (GR-G in Fig. 3) and the CE model fed by tectonic evidence (CE in Fig. 3). According to a geodetic model, the seismicity of the faults is derived from the geometric characteristics of the fault ruptures (see the electronic supplement ES1) and the regional/areal strain rates calculated from GNSS information (see the electronic supplement ES2). Instead, the tectonic model considers the CE with related recurrence intervals (see ES2) associated with each fault; all details are given in the following chapters.

\subsubsection{GR seismicity rates from observed seismicity on wide SZs}

The individual seismicity rates for each SZ, i.e., the number of events in each 0.3 magnitude bin, have been calculated from the TAP-DEC earthquake catalogue by the "highernot-highest " approach, developed for the seismic hazard map of the Italian territory (Slejko et al. 1998) in terms of $M_{W}$. In this approach, the seismicity rates are computed for all magnitude classes and several time intervals (among which those indicated by the analysis of completeness), all ending at the end of the catalogue. For each magnitude, the highest seismicity rate related to a time period not shorter than the complete one is selected as the rate of that magnitude. Additionally, if the selected rate corresponds to a recurrence interval 
(1/rate) shorter than the interval on which this selected rate is calculated, any rate referred to an interval richer of earthquakes but longer than that of the selected rate is finally chosen as seismicity rate of that magnitude class [more information and examples can be found in Slejko et al. (1998)]. This method is conservative: the seismicity rates are computed considering the completeness and the level of seismicity in different time periods.

There are different methodologies for assessing the $b$-value of the GR relation. The least squares method is often used, although not formally appropriate, since magnitude is not error free, cumulative event counts are not independent, and the error distribution of the number of earthquake occurrences does not follow a Gaussian distribution. In this study, we applied the maximum likelihood method, introduced by Aki (1965) and Utsu (1965), for which Weichert (1980) proposed a general routine suitable for different completeness periods of the earthquake catalogue. In the few cases (SZs x18, x19, x26, x34, where x stands both for 1 and 2, see Fig. 6) where the regression line overestimates notably the observed seismicity rates, this fact has been associated with a lack of low magnitude events, possibly due to an incompleteness in the earthquake catalogue, caused by unsatisfactory seismological monitoring in the region. For the sources where a low number of seismicity rates or a disagreement between the regression line and the observed seismicity rates have been identified (SZs x16, x17, x18, x19, x26, x29, x34, x35, x36, x37, x50, x51, x54 , x58, x59), a merging of neighbouring SZs has been applied $[(x 16+x 17),(x 18+x 19)$, $(x 26+x 34),(x 29+x 54),(x 35+x 36+x 37)$ see Fig. 7, (x50+x51+x58 + x59)]. The minimum magnitude value is fixed at 4.0, except for few cases (SZs x02, x03, x04, x17, x3 $5)$ according to the range of the available seismicity rates. Electronic supplements ES3 and ES4 contain the $a$ - and $b$-values calculated for the SZs of Z100 and Z200 zonations.

Figures $8 \mathrm{a}$ to d show the $a$ - and $b$-values obtained for the zonations Z100 and Z200, respectively. The little differences relate only to Albania, where transverse SZs have been introduced in Z100. It can be seen that a high $a$-value $(>5)$ is found in Italy and in the Adriatic Sea, where the $b$-value is also quite high ( $>1.1)$. Conversely, Albania is characterised by average $a$ - $(>3.5)$ and $b$ - (>0.9) values. Greece shows average $a$-values and $b$-values moderately high. This situation implies that the number of large events is proportionally low in Italy and the Adriatic Sea, whereas it is large in Albania.

\subsubsection{GR seismicity rates from fault activity evidence}

This approach has been applied in the European SHARE project (Giardini et al. 2014), and it is based on information about the 3D geometry of the active fault surface and the slip rate. The original idea was formulated by Anderson and Luco (1983), who proposed three categories of models for defining a magnitude recurrence distribution from the geological slip. In the first model, the recurrence is related to the entire fault (or fault segment) rupture, while the second and third models relate the recurrence to the rupture area of the maximum earthquake, and this magnitude could be associated with the geometry of the (entire or segmented) fault.

The estimation of the activity rates $(N(M)$, e.g., the annual number of earthquakes with a magnitude larger than, or equal to, $M$ ), involves parameters that come from the definition of the seismic moment $\left(M_{0}\right)$ for a particular event (Aki and Richards 2002), as the rigidity or shear modulus, the average displacement across the fault, the rupture area, and the geological (annual) slip rate, assuming conservatively that all the fault slip occurs seismically and ignoring possible aseismic creep. For the TAP calculations, we used the first Anderson and Luco (1983) formulation, as proposed by Bungum (2007): 

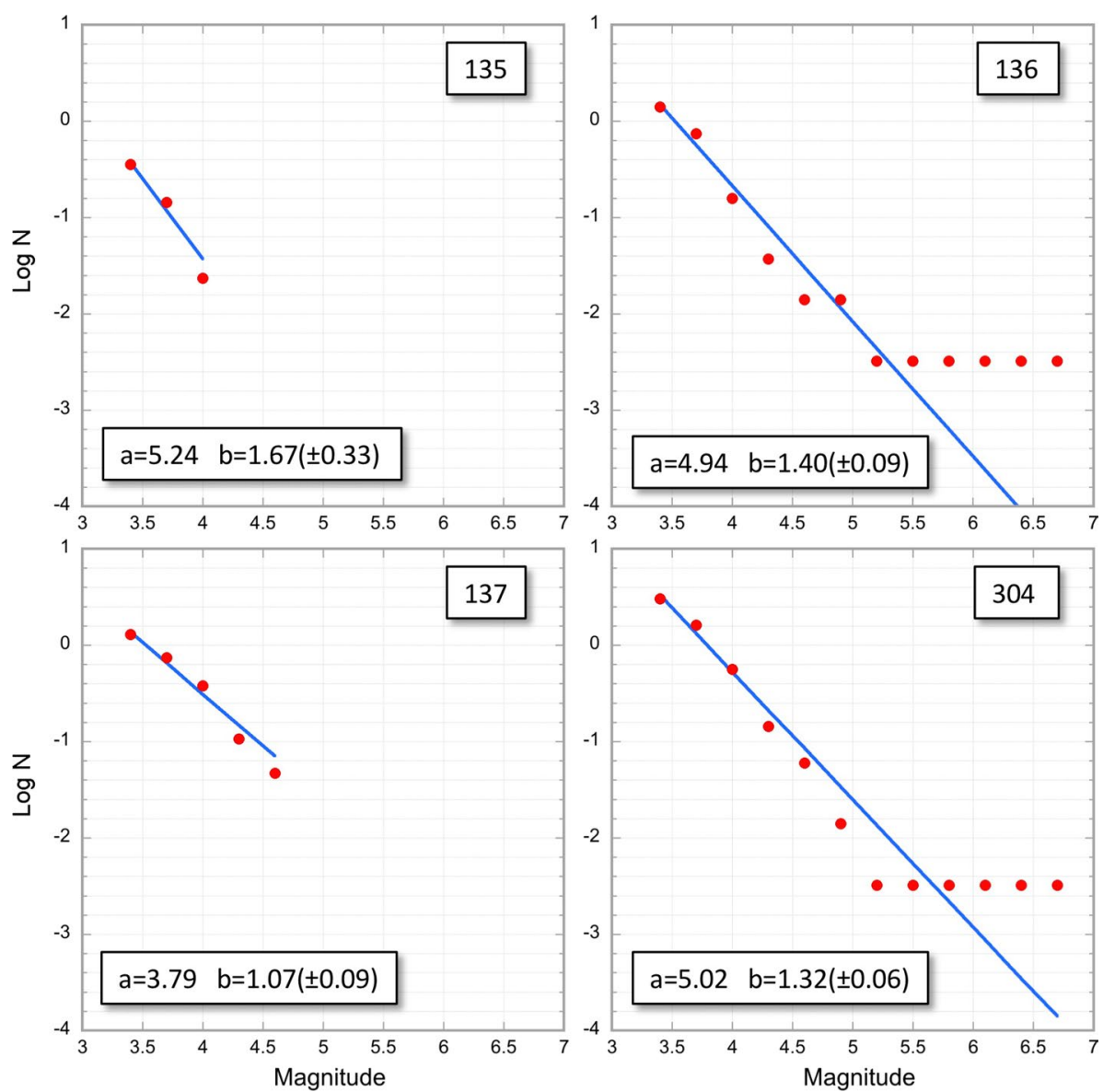

Fig. 7 Seismicity rates and GR fit for three SZs which have been merged because of few earthquakes: a SZ 135; b SZ 136; c SZ 137; d cumulated rates

$$
N(M)=\left(\frac{\bar{d}-\bar{b}}{\bar{d}}\right)\left(\frac{S}{\beta}\right) \mathrm{e}^{\bar{b}\left(M_{\max }-M\right)} \mathrm{e}^{-\left[(\bar{d} / 2) M_{\max }\right]}
$$

with:

$$
\begin{aligned}
& \bar{b}=b[\ln (10)] \\
& \bar{d}=d[\ln (10)] \\
& \beta=\sqrt{\left[\alpha M_{0}(0)\right] /(\mu W)} \\
& \alpha=D / L
\end{aligned}
$$

where $M_{0}(0)$ is the seismic moment for $M=0, b$ is the $b$-value of the GR relation, $d$ is the magnitude scaling coefficient of the moment - magnitude scaling law (Kanamori and 


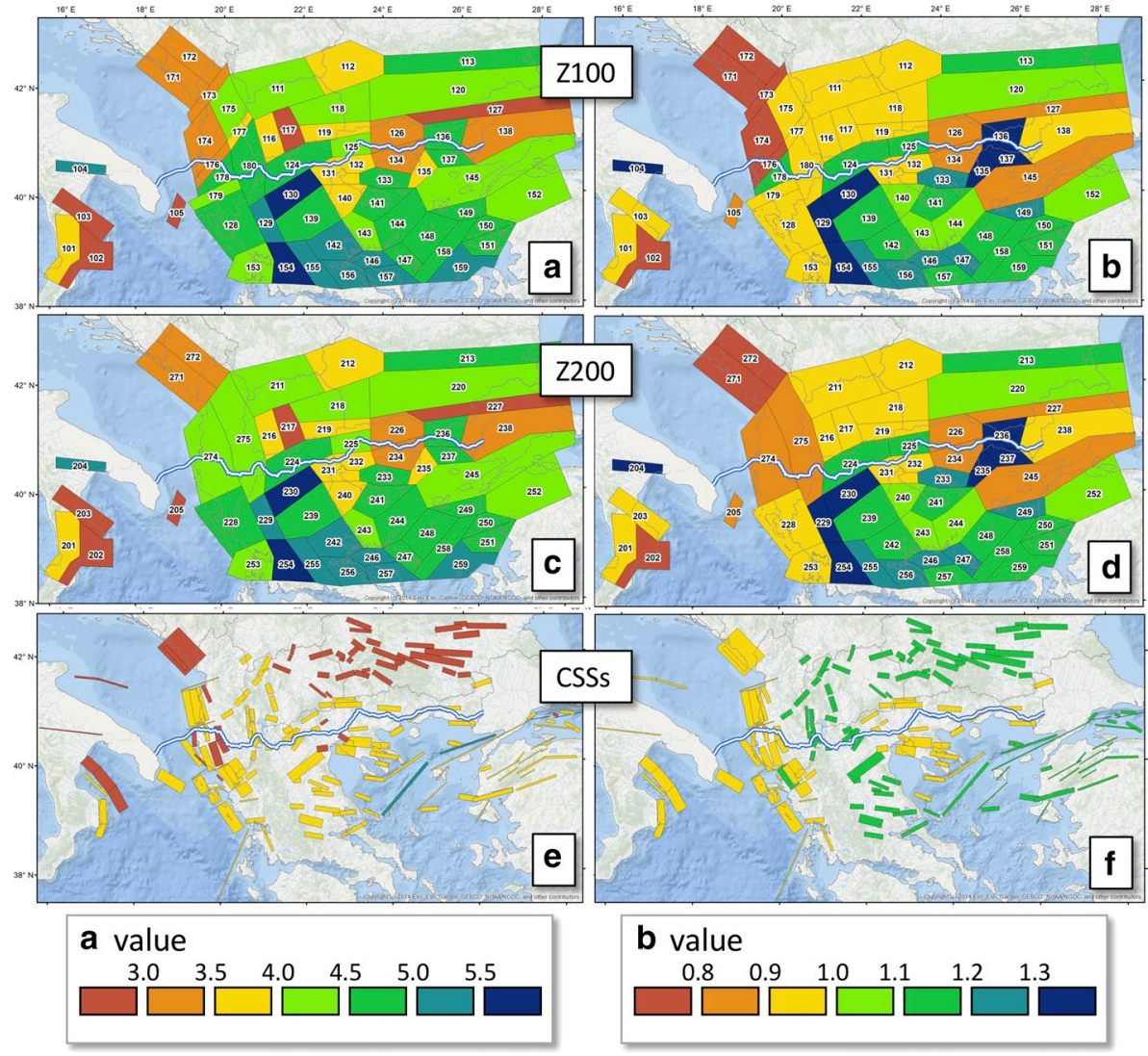

Fig. 8 GR parameters for the proposed SZs: a $a$-values for Z100; $\mathbf{b} b$-values for Z100; $\mathbf{c} a$-values for Z200; $\mathbf{d} b$-values for Z200; $a$-value for the CSSs; $\mathbf{f} b$-value for the CSSs. In double blue line the TAP corridor

Anderson 1975) and the value of the maximum magnitude $M_{\max }$ can be calculated by scaling laws between magnitude and fault dimensions (e.g., Wells and Coppersmith 1994).

The GR distributions are limited at the upper end by $M_{\max }$, assuming a sharp cut-off, and at the lower one by a threshold magnitude, usually around 4 to 5 . In our case, the threshold magnitude was fixed at 4 , the $b$-values (Fig. 8f) were obtained from the recorded seismicity in six wide background zones (see Fig. 9), $M_{\max }$ was computed from the fault dimensions (i.e., area, from Wells and Coppersmith 1994) taking into account the fault type ( $\mathrm{N}=$ normal, $\mathrm{R}=$ reverse, $\mathrm{S}=$ strike-slip, see Fig. 2$)$, and the rigidity or shear modulus was computed using the European crustal model EPcrust (Molinari and Morelli 2011).

The GR parameters ( $a$-value, $b$-value, $M_{\max }$ ) and their uncertainties are reported in the electronic supplements ES5 and ES6 for the two fault models considered (with and without segmentation) and are depicted in Figs. 8e, f and 10. A general agreement between the $a$-values computed for SZs and CSSs can be identified for some areas (see Fig. 8), with low $a$-values in Montenegro (less than 3.5) and Italy (less than 4.0), and with average values in North Macedonia (between 3.5 and 4.5). In Greece and Bulgaria, the $a$-values for the CSSs are lower than those of the SZs. It should be noted that the data sources (seismicity and slip rates), the approach, and the spatial attribution (wide SZs and CSSs) are completely 


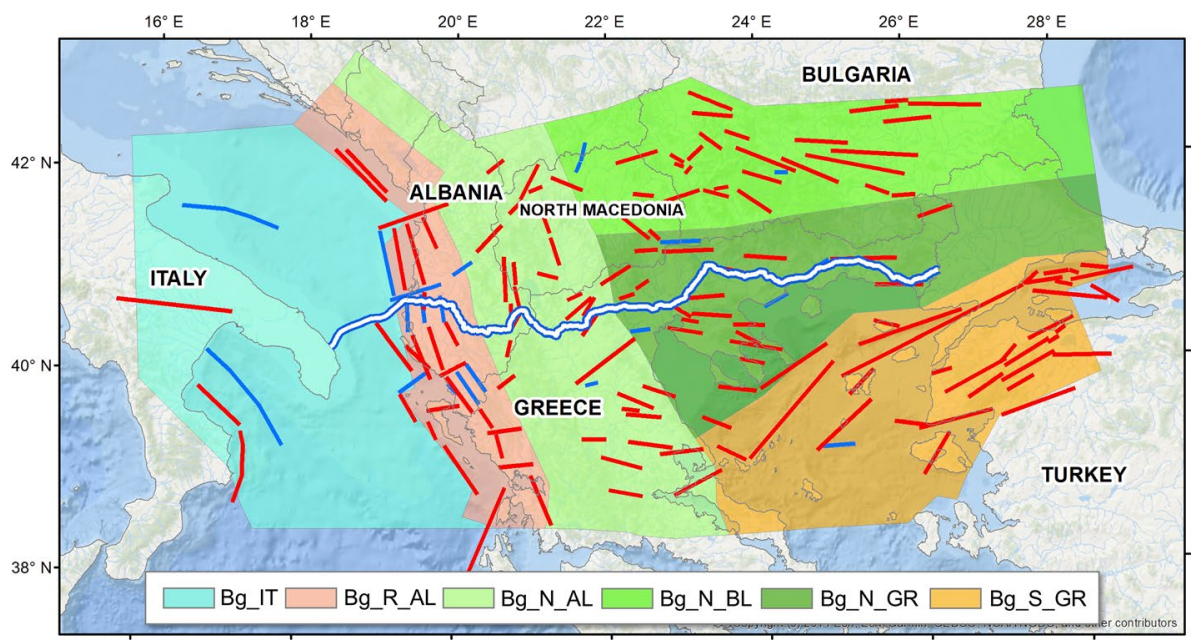

Fig. 9 Background zones and their kinematic character: cyan $($ Bg_IT $)=$ reverse and transcurrent for Italy offshore, pink $\left(\mathrm{Bg} \_\mathrm{R} \_\mathrm{AL}\right)=$ Albania reverse, pale green $(\mathrm{Bg}$ _N_AL) $=$ Albania normal; medium green $\left(\right.$ Bg_N_BL) = Bulgaria normal; dark green $\left(\right.$ Bg_N_GR) $=$ Greece normal; yellow $\left(B g \_S \_G R\right)=$ Greece strike-slip. Red lines are active faults, blue lines are silent faults. $\mathrm{Bg}$ stands for background zone, $\mathrm{R}$ for reverse, $\mathrm{N}$ for normal, $\mathrm{S}$ for strike-slip. In double blue line the TAP corridor

different. A general agreement can also be found for the $b$-values in Italy, along the Balkan coast (both with values lower than 1.0), and in Bulgaria (values between 1.0 and 1.2).

\subsubsection{Characteristic earthquake model}

The CE model was introduced by Schwartz and Coppersmith (1984) for the seismicity of the Wasatch and San Andreas faults in California and states that each fault can produce events of a specific narrow range of magnitude, in agreement with the geometric dimensions of the possible ruptures along the fault. A similar model (maximum magnitude model) was also suggested by Wesnousky (1986) for the seismicity associated with the faults in California. Meanwhile, Youngs and Coppersmith (1985) defined the probabilistic distribution for a model with a GR distribution for weak and moderate earthquakes and a CE (uniform) distribution for the high magnitudes: the authors called also this CE model. According to this model, Wells and Coppersmith (1994) developed scaling laws between the fault-rupture dimensions and the related characteristic magnitude. The difficulty of associating earthquakes to faults does not allow the seismologists to ultimately decide whether this model is valid worldwide, only for some faults or never. In any case, its likelihood is quite good and both DISS (Basili et al. 2008) and GreDaSS (Caputo and Pavlides 2013) are based on this model. Without entering into the scientific debate on the validity of the CE model, supported by observational data (Swan et al. 1980; Papageorgiou and Aki 1983) but also challenged (Grant 1996; Bakun et al. 2005), the estimation of the maximum expected magnitude for a fault is based on the expected rupture geometries, in terms of rupture length or rupture area, available from direct observations only for some recent events.

The fault databases report the parameters for the geometric definition (length, width, etc.) and the information on the activity, from paleoseismological surveys, or geodetic 

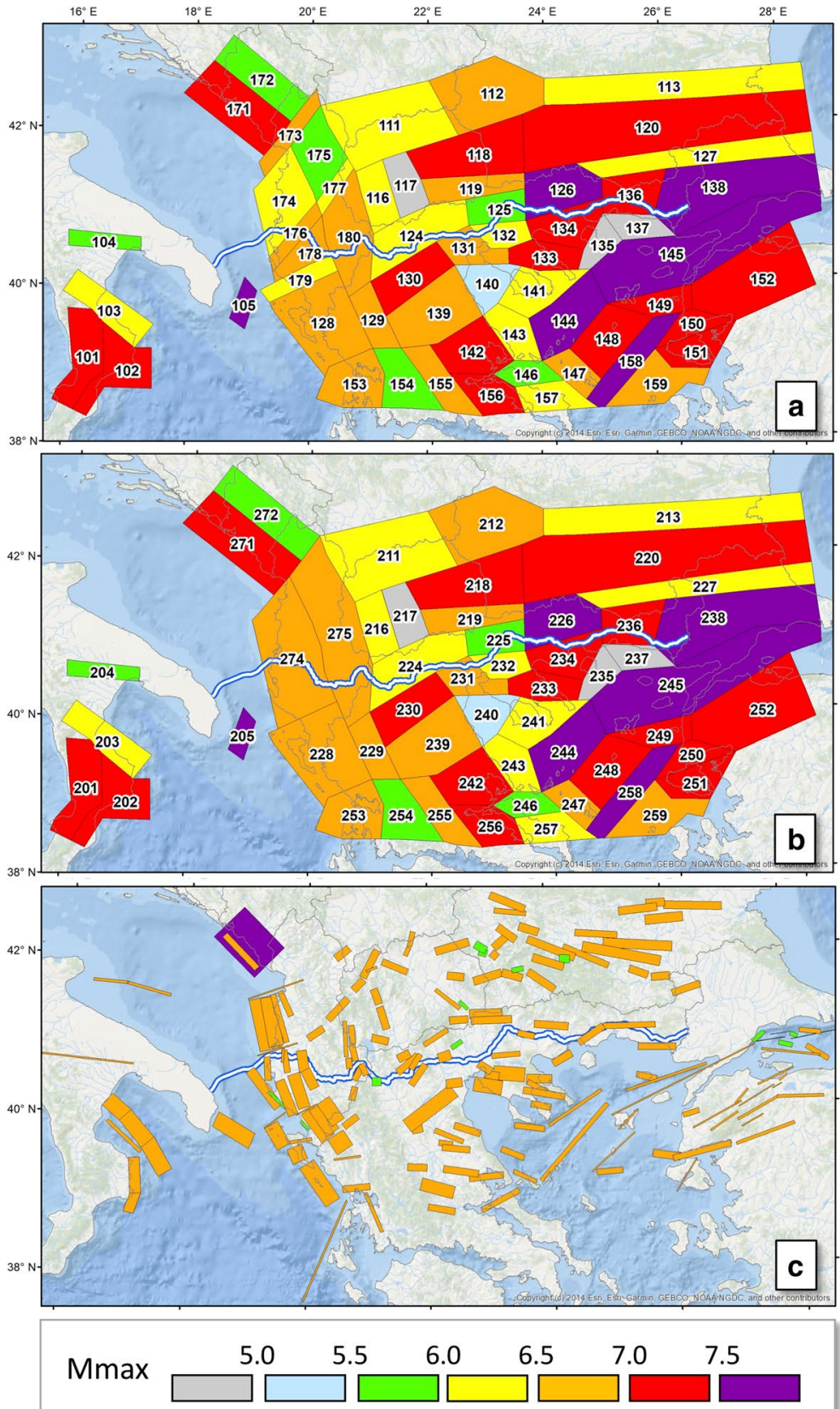

Fig. $10 M_{\max }: \mathbf{a}$ for Z100; $\mathbf{b}$ for Z200; $\mathbf{c}$ for the faults. In double blue line the TAP corridor 
measurements, of all CSSs of Fig. 2 (see ES1 and ES2), that are associated with the actual faults, whenever their possible segmentation is suggested. From those parameters, the characteristic magnitude can be estimated. The recurrence interval, i.e., the mean time period of repetition of the $\mathrm{CE}$, has been taken directly from the fault database (see ES2). It is assessed in different ways: inferred from slip rate and average displacement, based on paleoseismology (4000 years preferred), on geological constraints, derived from slip rate and slip per event, or modelling of marine terraces. It is well known (e.g., Nicol et al. 2005) that recurrence intervals and average displacements obtained in such a way are affected by large uncertainties and, consequently, the related hazard results should be considered our best estimates.

Two scenarios have been considered for the active faults (solid lines in Fig. 2) and the silent faults (dashed lines in Fig. 2): the absolute scenario, where the rupture length corresponds to the whole fault length, originating the largest possible magnitude for those fault dimensions; and the segmented scenario, where only a part of the fault ruptures, according to a segmentation scheme based on geologic/geodetic considerations (Caputo and Pavlides 2013).

Also, six background zones have been introduced: they collect the low seismicity not linked to any CSS (Fig. 9). More precisely, the events in each background zone with a magnitude lower than the minimum characteristic magnitude of the faults of the zone were fitted according to the GR model, and this seismicity has been treated in the PSHA elaboration in a zone-source fashion.

\section{4 $M_{\max }$}

To estimate $M_{\max }$, we applied a statistical approach (Kijko and Graham 1998) for the wide SZs, and a tectonic approach for the model based on faults.

The approach by Kjiko and Graham (1998) computes $M_{\max }$ for a source on a statistical basis using as input data: the maximum observed magnitude $\left(M_{\text {maxobs }}\right)$; the threshold magnitude considered complete in the catalogue; the average error in the magnitude estimates (fixed in our case arbitrarily at 0.2 ); the $b$-value of the GR relation and its SD; the annual rate (i.e., the number of earthquakes with magnitude greater than, or equal to, the threshold magnitude); and the catalogue time span which is considered complete. This last parameter was set equal to the completeness period of $M_{\text {maxobs }}$. Four formulations for $M_{\max }$ computation are implemented in the method; we applied here the Bayesian formula of Kijko and Sellevoll (1989). The $M_{\max }$ values estimated for each SZ are reported in the electronic supplements ES3 and ES4 and mapped in Figs. 10a and b for the two zonations Z100 and Z200. The highest values of $M_{\max }$ (larger than 7.0) are found along the Montenegro coast, in the easternmost sector of the TAP route in Greece and eastwards (Figs. 10a and b), where the North Anatolian Fault and its continuation along the North Aegean Trough dominate the tectonic framework. The highest expected $M_{\max }$, i.e., even larger than 7.5 is in the area north of Thessaloniki and the border area with Turkey (Figs. 10a and b) crossed by the TAP. Z200 determines that the whole of Albania shows an expected $M_{\text {max }}$ between 6.5 and 7.0 (Fig. 10b) instead of only the sector affecting the TAP route (Fig. 10a). In a few SZs, $M_{\max }$ results were extremely low (see grey and pale blue SZs in Figs. 10a and b), mainly because of the poorly documented seismicity and, consequently, the limited range of magnitude classes. A check has been done by increasing $M_{\max }$ to 5.5, but no difference was observed in the computed seismic hazard. 
For the models based on faults, we estimated $M_{\max }$ according to the dimensions of the fault and the fault type (N, R, S) using the Wells and Coppersmith (1994) scaling laws. However, since the Wells and Coppersmith (1994) scaling laws consider the rupture length, we made some considerations about the possible fault segmentation. Thus, we have an $M_{\text {max }}$ based on the full rupture along the fault length, and a credible $M_{\max }$ based on the rupture length derived by the expected segmentation of the fault. These two values of $M_{\max }$ are reported in the electronic supplements ES5 and ES6. The values of $M_{\max }$ for the CSSs are almost all between 6.5 and 7.0 (Fig. 10c), in agreement with those of the SZs along the Balkan coast.

\subsection{GMMs}

The choice of the GMMs suitable for the PSHA is an important issue, and some guidelines should be followed (Cotton et al. 2006). The selected GMMs should be exhaustive and mutually exclusive in the logic tree approach, and their number should be the smallest needed to capture the range of future ground motions. The main criteria for the selection are: compatibility of the tectonic regime, international appreciation, robustness of calibration data, and parameter suitability. We explored the GMM list collected by Douglas (2011) and, according to the above cited criteria, selected one global GMM and one regional GMM, suitable for the study region: the A\&B and the D\&T GMMs. The A\&B GMM is calibrated on 532 strong motion data from Europe and Middle East in the 5.0-7.6 $M_{W}$ range, uses the Joyner and Boore (1981) metrics for distance and parameters for fault style and site conditions are available. The D\&T GMM is calibrated on 335 Greek strong motion data in the 4.5-6.9 $M_{W}$ range, uses the epicentral distance and parameters for fault style and site conditions are available. The two GMMs are calibrated almost on different data (mutually exclusive) and represent the minimum number of models representing the ground motion of the study region (exhaustive). Both GMMs treat $M_{W}$ and have parameters for fault style and site conditions without asking additional unknown parameters. The difference in the distance metrics is not crucial in the case of wide SZs, while it could introduce some differences in the case of fault; in our case, the CSSs represent something wider than actual faults.

In the magnitude range 4.0 to 5.4 , where the A\&B GMM is not, or poorly, constrained, we adopted the Bragato and Slejko (2005, hereafter B\&S) GMM calibrated on weak motions. Considering the role of the Adriatic Moho in the attenuation, we extrapolated the ground motion at a $70-\mathrm{km}$ distance as far as a $200-\mathrm{km}$ distance following Bragato et al. (2011) in both GMMs.

All the cited GMMs were defined for PGA, SA, and PGV: SA at $0.2 \mathrm{~s}$ (SA0.2) and $1.0 \mathrm{~s}$ (SA1.0) are the spectral ordinates considered in the elaborations provided for the TAP route. Both A\&B and D\&T GMMs are defined for different tectonic styles and they have been applied in agreement with the tectonic style associated with the faults of Fig. 2.

The extrapolation of GMMs both in magnitude and distance is a delicate operation and needs a robust control, although in the standard PSHA it does not play a strategic role, because the contribution of very large magnitude events is limited. As a few events exceed the magnitude range where the A\&B and D\&T GMMs are defined (7.6 and 6.9, respectively), we have checked if the cited GMMs can be extrapolated outside their upper magnitude range, an operation always considered acceptable by Ambraseys (1995).

The two chosen GMMs, in terms of median values of PGA, are quite similar in the range of $M_{W} 5.5$ to 6.5 outside the near field (Fig. 11). At $M_{W} 4.5$ the A\&B GMM, 
Fig. 11 Comparison between the D\&T and A\&B GMMs

for reverse faulting and four magnitudes $(4.5,5.5,6.5,7.5)$. The PGA value is fixed from a 70- to a 200-km distance (see the text for the explanation). For $M_{W}$ less than 5.5, the A\&B GMM is substituted by the B\&S GMM

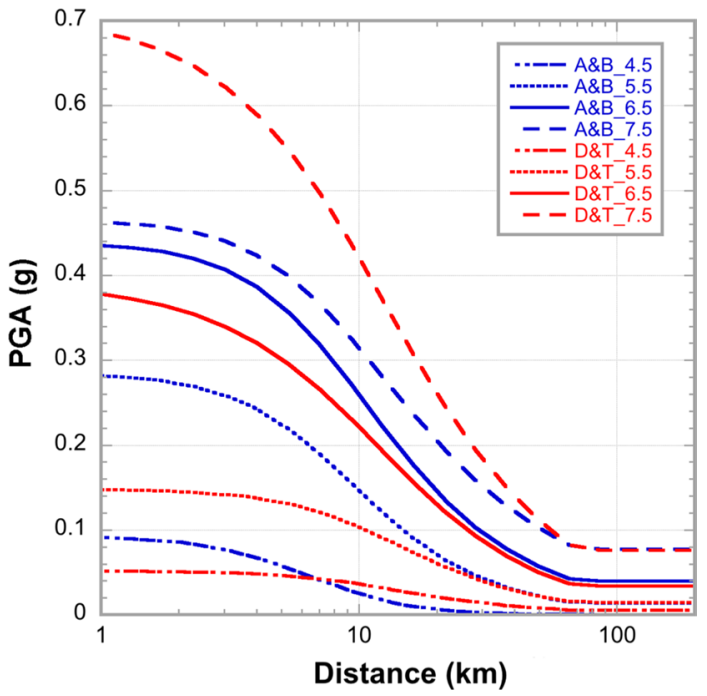

corrected according to the B\&S one, produces lower shakings than the D\&T GMM for distances larger than $10 \mathrm{~km}$, but in both cases, the values are very low (less than $0.01 \mathrm{~g}$ ). A quite large shaking is modelled by the D\&T model for $M_{W} 7.5$, where the data do not constrain the cited GMM. A comparison between the two GMMs at 6.9, where both are valid, has shown, however, that the D\&T model gives a PGA larger of about $0.3 \mathrm{~g}$ in the near field. Similar considerations also hold for the spectral acceleration. To avoid the problematic extrapolation of the D\&T GMM, a correction in agreement with the behaviour of the A\&B model has been applied. More precisely, the D\&T model has been considered valid for $M_{W} 7.0$ (actually the maximum $M_{W}$ where the relation is calibrated is 6.9). Considering that A\&B GMM is calibrated for $M_{W} 7.6$, the percentage of increment in the A\&B GMM between $M_{W} 7.0$ and 7.5 has been applied to the D\&T model. In such a way, the high values given by the D\&T model are limited, although a difference of about $0.2 \mathrm{~g}$ remains as it is motivated by the values of the two GMMs at $M_{W} 6.5$, where both are validated. This last version of modified GMMs has been applied in the PSHA (Fig. 11).

\section{Results and discussion}

An updated 2012 version of the computer code Crisis (Ordaz et al. 2013) was applied for all the elaborations: it considers as sources both wide zones, and 3D faults, and for the seismicity both a GR model and a CE model. The results refer to the computations performed considering the different source and seismicity models. The following return periods (RPs) have been chosen, and they correspond to specific levels of exceedance probability in 50 years (T50, considered as the standard lifetime for a residential building): 475 years (corresponding to probability 0.10 in T50), 975 years (corresponding to 0.05 T50), 2475 years (corresponding to 0.02 T50), 4975 years (corresponding to 0.01 T50), and 9975 years (corresponding to 0.005 T50). The final results are aggregated by a proper weighting of the different branches of the logic tree (Fig. 3). 

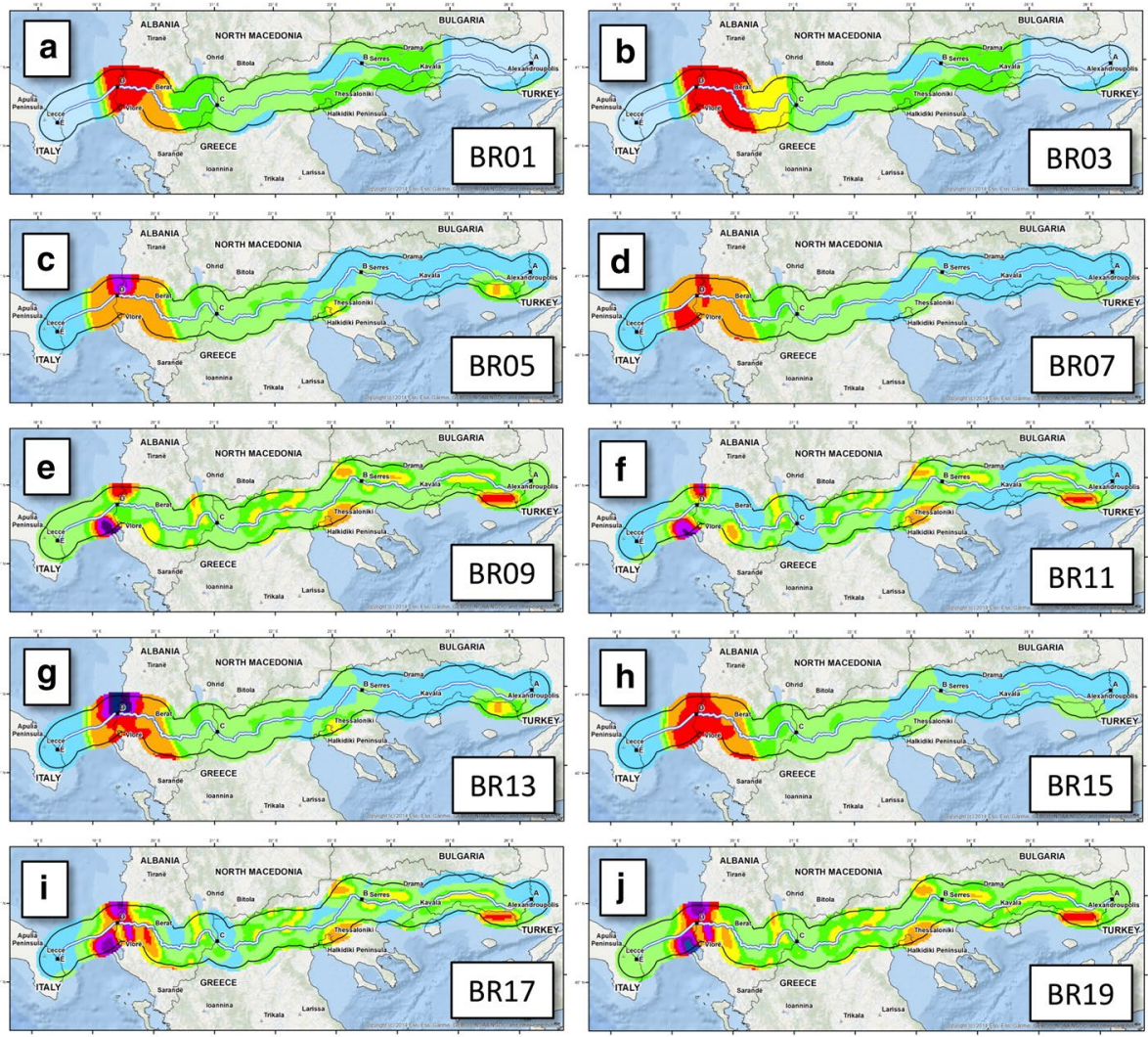

$\begin{array}{lllllllllllll}0.1 & 0.2 & 0.3 & 0.4 & 0.5 & 0.6 & 0.7 & 0.8 & 0.9 & 1.0 & 1.1 & 1.2 & (\mathrm{~g})\end{array}$

PGA 2475 Rock

Fig. 12 PGA with a 2475-year return period with the A\&B GMM. The ten maps refer to the odd ten branches (BR in the figure) of the logic tree (Fig. 3), identified by the number in each panel

Before presenting the final estimated ground motions along the TAP route, we show the results obtained by the individual branches, to highlight the differences produced by the different choices in the input data.

The ground motions of the 20 branches of the logic tree (Fig. 3) for a 2475-year RP are plotted on a $50-\mathrm{km}$ wide ( $25 \mathrm{~km}$ on both sides) strip around the TAP route (Figs. 12 and 13): the 2475-year RP is considered the adequate RP for ground shaking hazard along a pipeline (Golara 2014) and the choice of the 50-km wide corridor is motivated by the possibility to show the pattern of the shaking. The results are displayed in maps, in terms of PGA values, for different combinations of the model parameters. No value interpolation was applied and the computed results are mapped simply as data posting. Figure 12 corresponds to the ten branches that consider the A\&B GMM, while Fig. 13 refers to the corresponding results for the D\&T GMM. The first evidence is that the A\&B GMM produces higher values with respect to the D\&T GMM, regardless of the models selected, except in two cases, where the CE model is associated with a fault segmentation (compare Figs. 12c with $13 \mathrm{c}$ and $12 \mathrm{~g}$ with $13 \mathrm{~g}$ ). In these cases, this is due to the combined effect of the D\&T GMM associated with the high magnitude of the fault segments. The influence of the two 

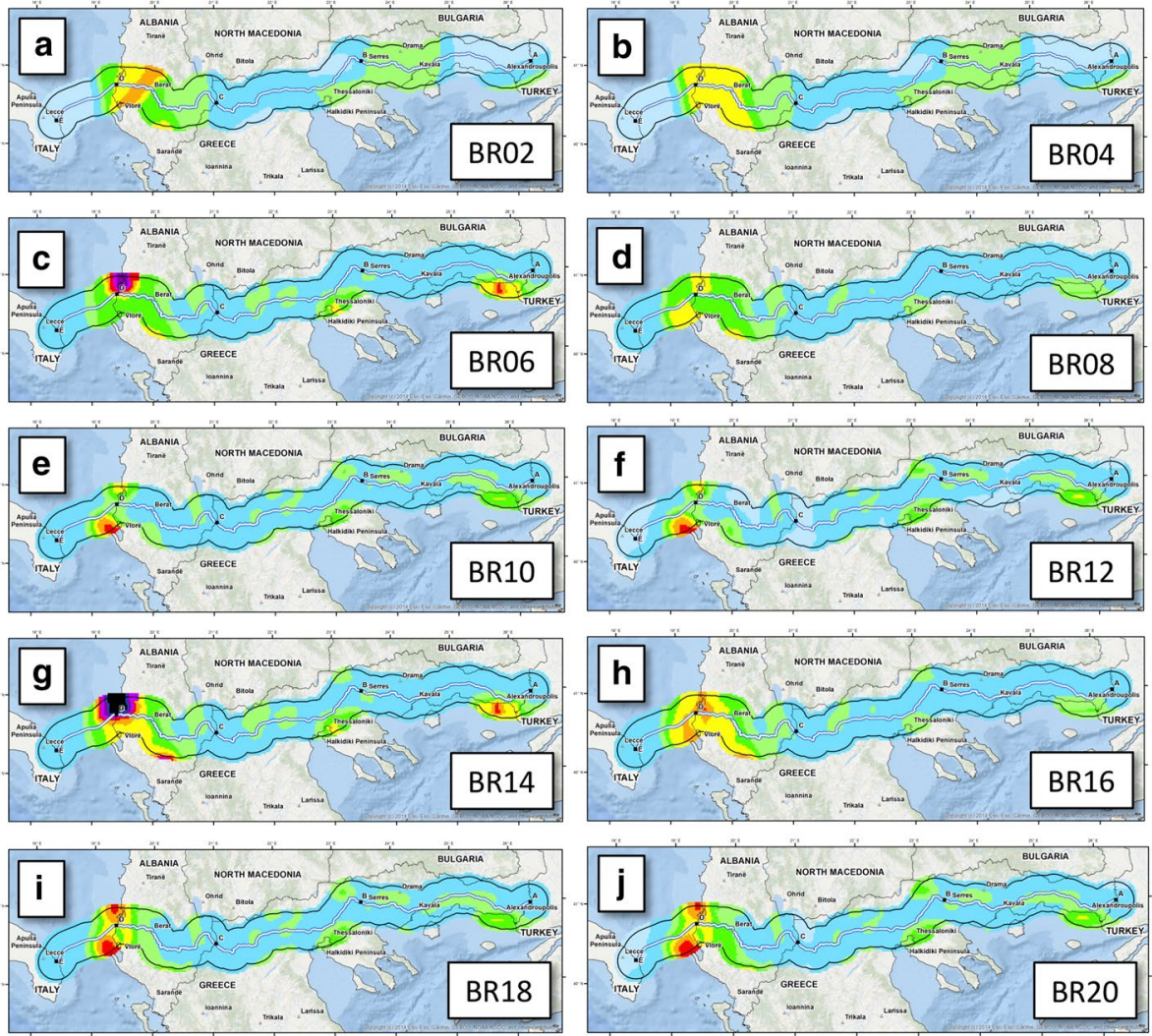

$\begin{array}{lllllllllllll}0.1 & 0.2 & 0.3 & 0.4 & 0.5 & 0.6 & 0.7 & 0.8 & 0.9 & 1.0 & 1.1 & 1.2 & (\mathrm{~g})\end{array}$

PGA 2475 Rock

Fig. 13 PGA with a 2475-year RP with the D\&T GMM. The ten maps refer to the even ten branches (BR in the figure) of the logic tree (Fig. 3), identified by the number in each panel

source models depends on the other models considered and the model with wide SZs gives high PGA values in large regions (Figs. 12a, b, 13a, b), while the model based on faults produces high values only in limited areas. The introduction of transversal SZs (zonation Z100) has a more significant effect on the PSHA results when the D\&T GMM is employed (compare Figs. 13a and $b$ ) than with the A\&B GMM (compare Figs. 12a and b). The contribution of the silent faults, when added to the active fault database, is not marginal, and locally increases the expected PGA values by $0.2 \mathrm{~g}$ (e.g., along the Albanian coast; compare Figs. $12 \mathrm{~g}$ to 1 with Figs. $12 \mathrm{c}$ to $\mathrm{f}$, and Figs. $13 \mathrm{~g}$ to 1 with Figs. $13 \mathrm{c}$ to f). The seismicity model [CE (Figs. 12c, d, 13c, and d) versus GR (Figs. 12e, f, 13e, and f)] applied to the fault source model, does not produce a systematic influence (increase or decrease) of the computed ground motions, but depends on the other models. In general, the model that considers fault segmentation (Figs. 12c, e, 13c, and e) results in slightly higher PGA levels than that without segmentation, again due to the high magnitude associated with the different fault segments.

The results from the twenty branches previously described have been aggregated according to the weights assigned to the branches (see the numbers at the nodes of the 

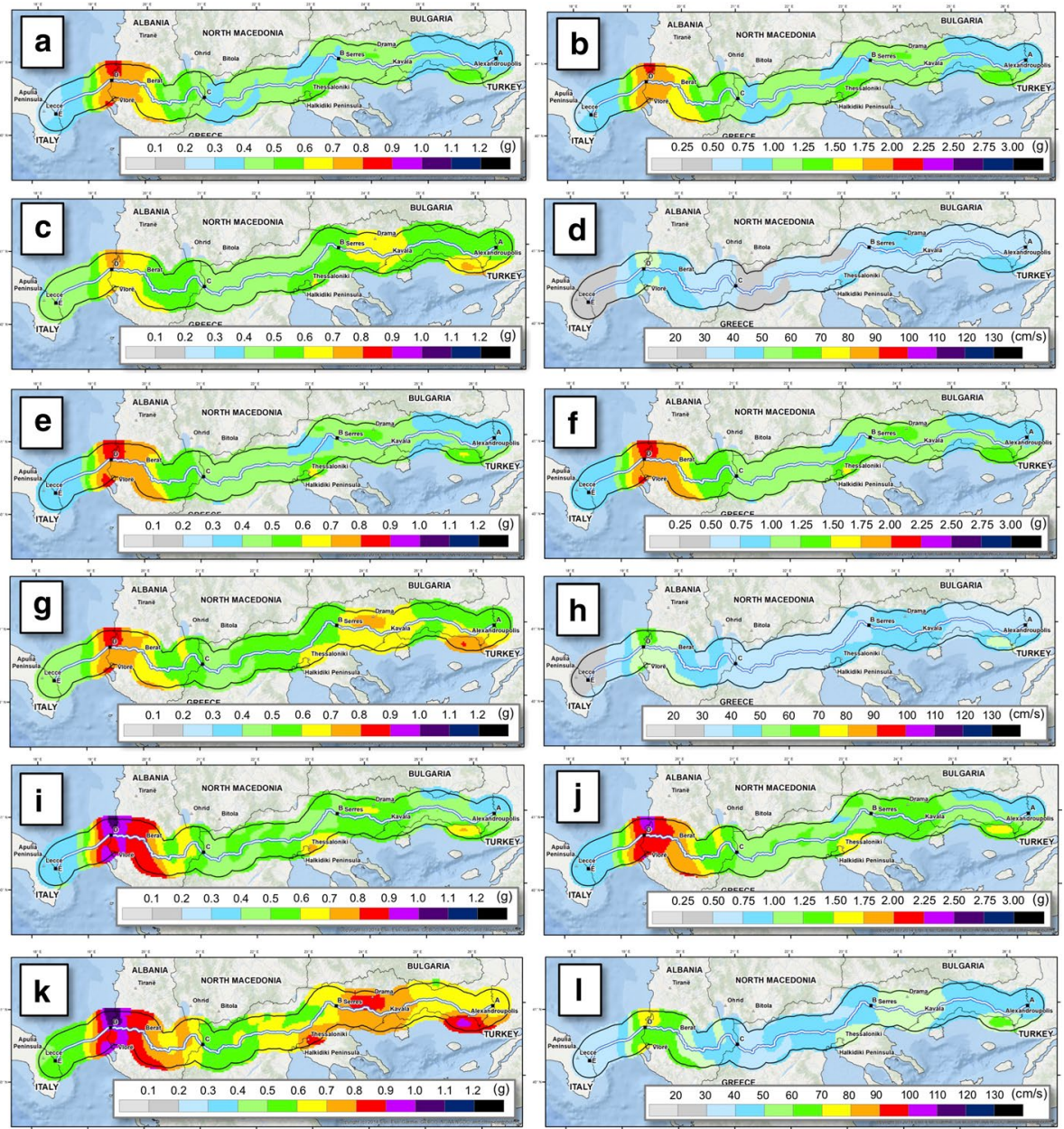

Fig. 14 Ground motions along the TAP route for $\mathrm{RP}=2475$ years and rock: a PGA; b SA0.2; $\mathbf{c}$ SA1.0; $\mathbf{d}$ PGV; stiff soil: e PGA; f SA0.2; g SA1.0; h PGV; and soft soil: i PGA; j SA0.2; k SA1.0; I PGV

logic tree in Fig. 3). Here, we show the complete suite of PSHA maps only for the 2475year RP for all considered parameters (PGA, SA0.2, SA1.0, PGV) for rock (Figs. 14a to d), stiff soil (Figs. 14e to h), and soft soil (Figs. 14i to l).

The largest PGA values for rock site geology are observed along the Albanian coast, west of Fier, with values ranging from 0.8 to $0.9 \mathrm{~g}$ (Fig. 14a). A secondary maximum is identified in a rather large area around Thessaloniki and at the Turkish border (SW of Alexandroupolis), with both sites showing much lower PGA levels (0.5 to $0.6 \mathrm{~g}$, see Fig. 14a). A similar pattern is shown by the SA0.2 map with values exceeding $2.0 \mathrm{~g}$ along the Albanian coast (Fig. 14b). The SA1.0 map (Fig. 14c) identifies also the Alexandroupolis area, at the Turkish border, at similar levels with the Albanian coast and values exceeding $0.7 \mathrm{~g}$, while the Greek sector north of Thessaloniki displays values slightly lower (between 0.6 and $0.7 \mathrm{~g}$ ). Moreover, the PGV map identifies the same sector of the Albanian coast as the most seismically active with values exceeding $50 \mathrm{~cm} / \mathrm{s}$ (Fig. 14d). 
A similar pattern is also revealed by the maps referring to stiff (Fig. 14e to h) and soft (Fig. 14i to 1) soil local geology with the maximum values increasing roughly by one class $(0.2 \mathrm{~g})$ in the case of stiff soil and two classes $(0.4 \mathrm{~g})$ in the case of soft soil with respect to the rock maps.

From the different seismic hazard curves related to the individual branches, all statistical percentiles have been calculated. A study test site was considered west of Fier, along the Albanian coast, where the main compressor station will be placed (see its location in Fig. 2). The seismic hazard curves for PGA, SA0.2, SA1.0, and PGV, obtained as weighted mean from the individual branches, are displayed in Fig. 15: each panel shows the mean seismic hazard curve for rock, stiff, and soft soil local geology conditions, together with the related uncertainties, represented by the SD obtained from the 20 branches of the logic tree (Fig. 3). In such a way, it is possible to evaluate the differences in the expected shaking caused by the various choices made at the nodes of the logic tree and quantify the total uncertainty in the final results. We adopt here the standard approach to present mean value plus $1 \mathrm{SD}$ results, though this (more conservative) is rarely adopted in seismic design practice. However, when the dispersion in the results of the different branches of the logic tree is relatively large, adopting a +1 SD limit for the PSHA results is a reasonable safety
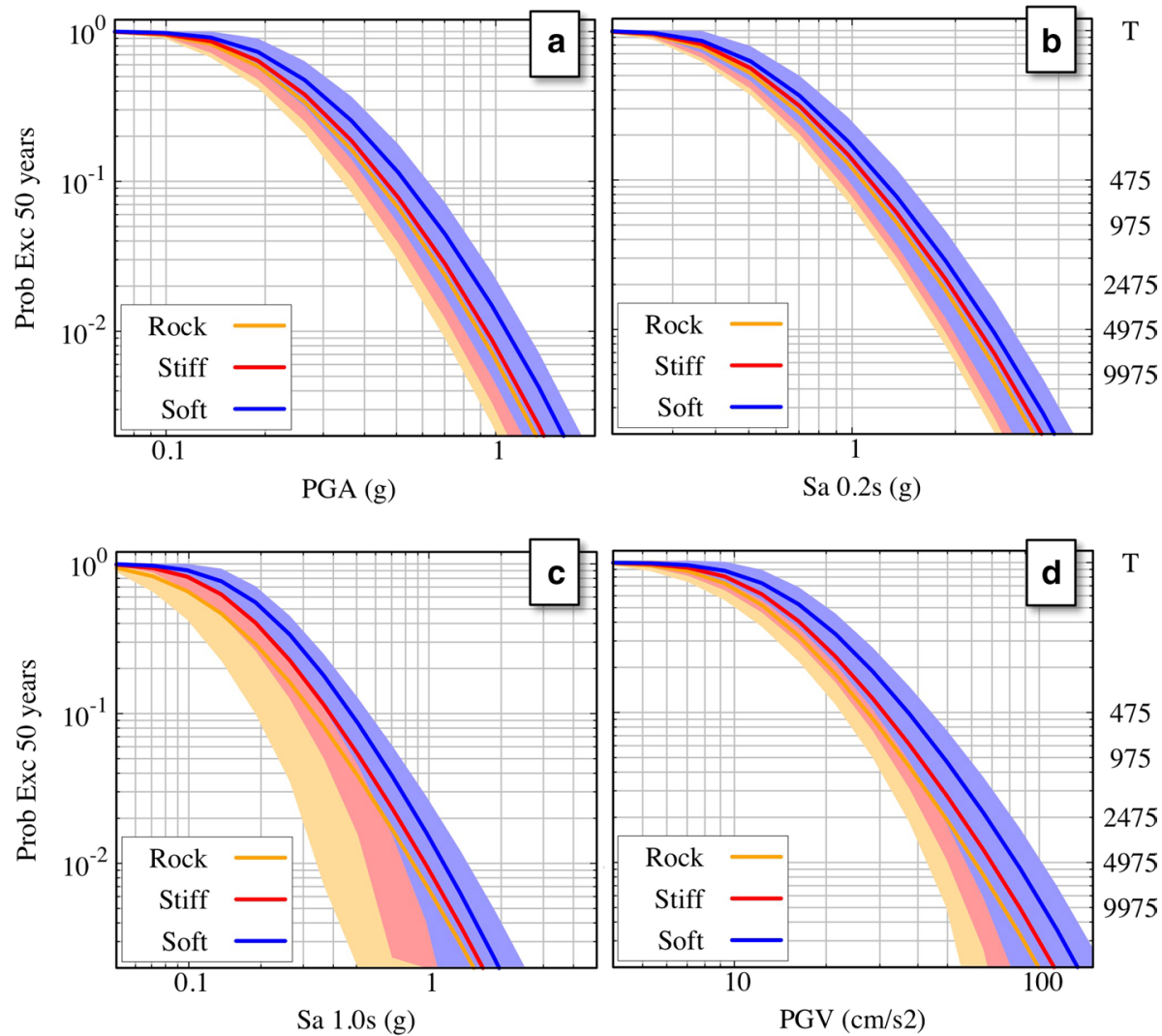

Fig. 15 Seismic hazard curves (in terms of exceedance probability in 50 years) for the Fier site (see its location in Fig. 2) for rock, stiff, and soft soils: a PGA, b SA0.2, c SA1.0, d PGV. The coloured (yellow = rock, red $=$ stiff, blue $=$ soft $)$ solid lines indicate the mean values and the coloured areas the related uncertainties 
measure: this is the main case for SA1.0 (Fig. 15c) and PGV (Fig. 15d). The curves related to rock and stiff soil local geology conditions are very similar for all considered quantities, while those for soft soil exceed the corresponding rock ones by roughly $20 \%$ to $40 \%$ for the different quantities examined.

Figure 16 shows the uniform hazard spectra (UHSs) calculated for the Albanian coast compressor test site. Figure 16a displays the results for the twenty branches and the corresponding mean value plus 1 SD for a 2475-year RP considering a rock site, while the other three panels show the UHSs for all investigated RPs (475, 975, 2475, 4975, and 9975 years) respectively for rock (Fig. 16b), stiff soil (Fig. 16c), and soft soil (Fig. 16d) local geology conditions. The weighted mean UHS is derived from two main families of spectra: those computed with the A\&B GMM and those calculated with the D\&T one. The corresponding results from the two families are notably different. In fact, the A\&B GMM emphasises the low periods (peak at $0.1 \mathrm{~s}$ ) while the D\&T one exhibits a maximum at $0.4-0.5 \mathrm{~s}$, hence, the resulting spectra are characterised by the presence of a quite large peak. The amount of the SD gives a clear idea about the uncertainty of the average spectrum. The reasons discussed above explain why the obtained UHSs are
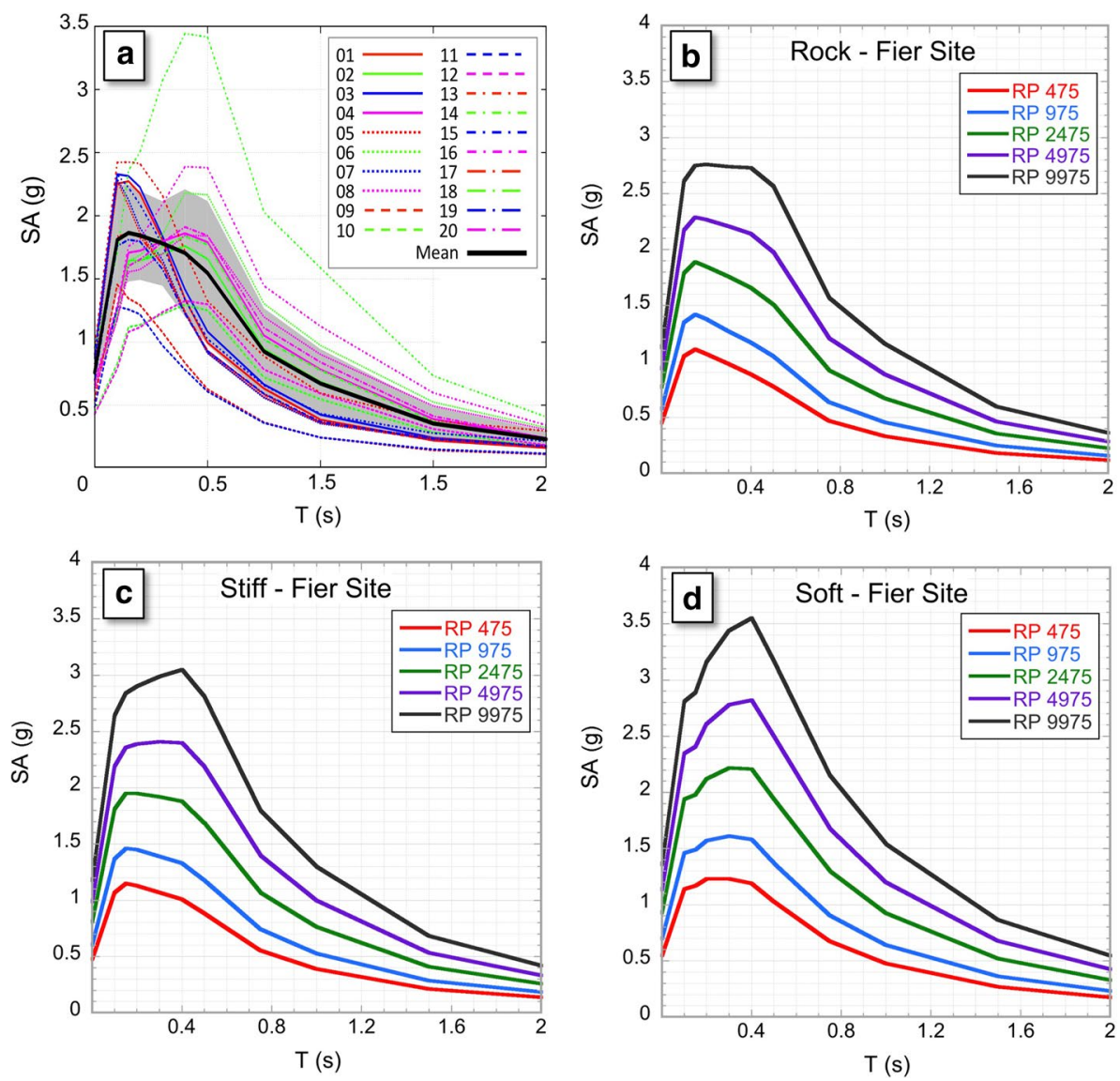

Fig. 16 UHSs for the Fier site (see its location in Fig. 2): a for a 2475-year RP (mean and 20 branches), rock conditions; $\mathbf{b}$ for different RPs, rock; $\mathbf{c}$ for different RPs, stiff soil; $\mathbf{d}$ for different RPs, soft soil 
generally characterised by a large dispersion among the different branches of the logic tree (Fig. 16a), justifying the use of the mean value plus one SD.

Considering the details of the obtained results, we see that the high dispersion is mainly caused by branch 14 , based on the CE model for seismicity with segmented rupture on active and silent faults, roughly $50 \%$ higher than the other spectra. This observation can be explained by the specific recurrence interval of the earthquakes associated with faults in the proximity of the site, and the large acceleration modelled by the D\&T GMM for $0.5 \mathrm{~s}$. The addition of one SD to the mean spectrum would be consistent with all the individual spectra except for three, with only one of them exhibiting a remarkably higher acceleration. The mean UHSs show a high hazard for all RPs with the dominant period of $0.15 \mathrm{~s}$. Also, the 0.4-s period becomes important at long RPs, causing an almost flat top for the 9975-year RP: this testifies the increasing contribution of distant seismicity with increasing RP. The maximum acceleration for a 2475 -year RP is reached at $0.15 \mathrm{~s}$ with a value of $1.9 \mathrm{~g}$ (Fig. 16b). The acceleration at 0.4-s period dominates instead in the UHS for stiff (Fig. 16c) and soft (Fig. 16d) soils.

The PSHA procedure also allows the computation of the mean annual rate of exceedance at a particular site, based on the aggregate hazard from potential earthquakes of many different magnitudes occurring at many different source-to-site distances. Therefore, the rate of exceedance computed in a PSHA is not associated with any particular earthquake magnitude or source-to-site distance. In some cases, however, it may be useful to estimate the earthquake magnitude and/or the source-site distance contributing most to hazard. These quantities may be used, for example, to construct ground shaking and risk scenarios, as well as to select existing ground motion records (recorded in earthquakes of similar magnitude at a similar source-site distance) for response analyses. The methodology to identify the largest contributor, in the set of all earthquakes constructing the hazard at a site, is called deaggregation, and was introduced by McGuire (1995). The deaggregation requires that the mean annual rate of exceedance be expressed as a function of magnitude and distance. The full analysis can be conducted simply by appropriately discretising the range of allowable magnitudes and distances (the reference binning values in our case were $\Delta m=0.3$ and $\Delta r \approx 10 \mathrm{~km}$ ). As the summation runs over all sources, in the case of many sources, placed at similar distances, it could be not trivial to identify the one hosting the dominant earthquake for the hazard at the site. The various sources must be, then, analysed individually.

The compressor station along the Albanian coast (see location in the inset of Fig. 2) has been considered for the PSHA deaggregation, i.e., for the identification of the dominant earthquake. The deaggregation has been performed on the source model based on faults, because when wide SZs are used the dominant quake results almost always in an event located under the site, if the site is contained into an SZ with activity similar to, or larger than, the surrounding ones, as in the present case. Two ground motions have been considered: SA0.2, which represents the high-frequency vibration, and SA1.0, representing the low-frequency vibration. In general, SA0.2 should be produced mainly by local earthquakes, while SA1.0 should be generated by more distant, strong quakes. The results suggest that the main contribution to hazard for the considered test site is given by local earthquakes respectively of $M_{W} 6.0$ and 6.6 for SA0.2 (Fig. 17a) and SA1.0 (Fig. 17b), respectively. This is not surprising if we consider the presence of the Vlore backthrust (A220 in Fig. 2) and the Fier thrust (A230 in Fig. 2) that have generated strong earthquakes in the past. On the basis of these results, we deemed that further investigation and detailed ground motion scenarios could provide a valuable contribution to the estimate of the seismic hazard of the test site area. Therefore, we performed 

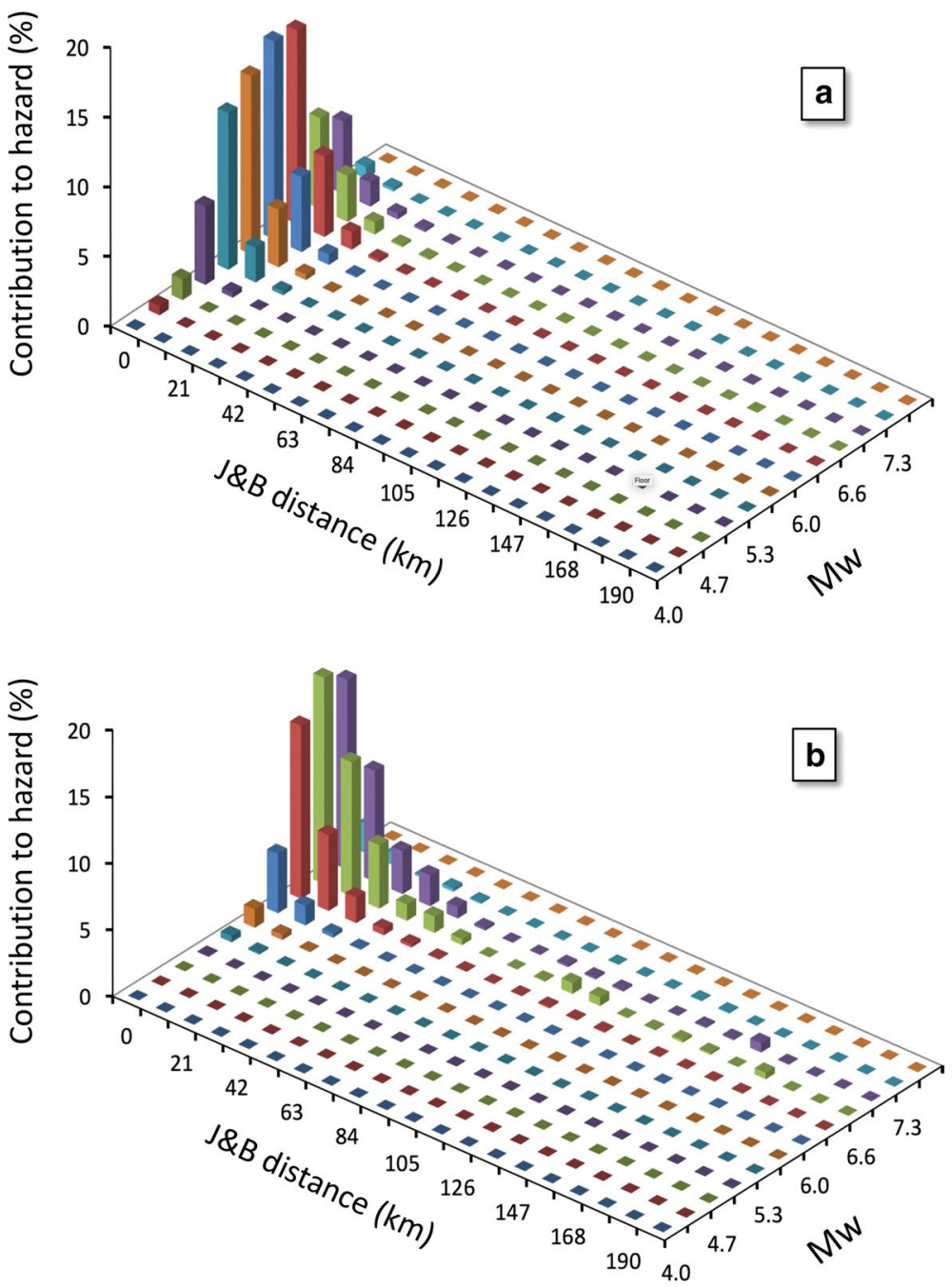

Fig. 17 Deaggregation for the Fier site (see its location in Fig. 2) and RP=2475 years: a SA0.2; b SA1.0

a deterministic seismic hazard assessment study, as reported in the companion paper by Moratto et al. (2020, this issue).

\section{Conclusions}

A comprehensive PSHA has been performed for the TAP route. This analysis consisted of the compilation of an earthquake catalogue suitable for the study and the definition of the (active and possibly active) faults that can contribute to the ground motion along the corridor. 
With the aid of an appropriate logic tree (Fig. 3), where different options have been considered for the main parameters involved in PSHA, the ground motion along the TAP route has been estimated in terms of PGA, SA0.2, SA1.0, and PGV (Fig. 14) for different RPs (475, 975, 2475, 4975, and 9975 years) and different local geology conditions (rock, stiff soil, and soft soil). The area with the highest hazard occurs west of Fier, along the Adriatic coast of Albania (PGA between 0.8 and $0.9 \mathrm{~g}$, SA0.2 between 2.0 and $2.25 \mathrm{~g}$, SA1.0 between 0.7 and $0.8 \mathrm{~g}$, and PGV between 50 and $60 \mathrm{~cm} / \mathrm{s}$, for an RP of 2475 years on rock), while strong ground motions are also expected for the area north of Thessaloniki, to the north of Kavala, in the southern Alexandroupolis area, as well as the border of Greece with Turkey (Fig. 14).

Moreover, a selected site along the TAP route with the highest expected ground motion (west of Fier) has been investigated in detail in terms of hazard curves (Fig. 15) and UHSs (Fig. 16). The earthquakes contributing most to the hazard of the test site at low and high frequencies ( 1 and $5 \mathrm{~Hz}$ ) have been identified by deaggregating the hazard results referred to the 2475-year RP (Fig. 17), and the corresponding design events for the TAP infrastructure have been identified as local quakes with $M_{W} 6.6$ and 6.0, respectively. For this site, detailed ground motion scenarios are needed to provide additional information and to better constrain the seismic hazard of the area.

The shaking values obtained in this study agree with the most recent large-scale investigations conducted in this area. Focusing on the Albanian coastal sector near the test site, the values according to the present study (Fig. 15) for a 475-year RP on rock are 0.42 , 0.31 , and $1.1 \mathrm{~g}$, respectively for PGA, SA1.0, and SA0.2 while those on stiff soil are 0.45 , 0.40 , and $1.2 \mathrm{~g}$. For the same RP, the estimates of the SHARE project (Giardini et al. 2014) on rock are between 0.4 and $0.425 \mathrm{~g}$, around $0.25-0.275 \mathrm{~g}$, and $0.8 \mathrm{~g}$ for PGA, SA1.0, and SA0.3, respectively. A previous similar study (Jimenez et al. 2001) gives values around $0.5 \mathrm{~g}$ for PGA, $0.3 \mathrm{~g}$ for SA1.0, and $1.0 \mathrm{~g}$ for SA0.3, respectively, for the same RP, but for stiff soil.

Supplementary Information The online version contains supplementary material available at https://doi. org/10.1007/s10518-021-01111-2.

Acknowledgements Many thanks are due to P. Bragato, OGS, who contributed to developing ground motion models. This study was performed within the project "TAP Project-Trans Adriatic Pipeline Seismological Investigation" for E.ON New Build \& Technology GmbH, Geisenkirchen, Germany. We acknowledge the two excellent reviewers who improved notably the manuscript with very useful comments.

Funding Open access funding provided by Istituto Nazionale di Oceanografia e di Geofisica Sperimentale - OGS (National Institute of Oceanography and Applied Geophysics) within the CRUI-CARE Agreement.

Open Access This article is licensed under a Creative Commons Attribution 4.0 International License, which permits use, sharing, adaptation, distribution and reproduction in any medium or format, as long as you give appropriate credit to the original author(s) and the source, provide a link to the Creative Commons licence, and indicate if changes were made. The images or other third party material in this article are included in the article's Creative Commons licence, unless indicated otherwise in a credit line to the material. If material is not included in the article's Creative Commons licence and your intended use is not permitted by statutory regulation or exceeds the permitted use, you will need to obtain permission directly from the copyright holder. To view a copy of this licence, visit http://creativecommons.org/licenses/by/4.0/. 


\section{References}

Aki K (1965) Maximum likelihood estimate of $\mathrm{b}$ in the formula $\log \mathrm{N}=\mathrm{a}-\mathrm{bM}$ and its confidence limits. Bull Earthq Res Inst 43:237-239

Aki K, Richards PG (2002) Quantitative Seismology, 2nd edn. University Science Books, Sausalito, CA

Akkar S, Bommer JJ (2010) Empirical equations for the prediction of pga, pgv, and spectral accelerations in Europe, the Mediterranean Region, and the Middle East. Seismol Res Letter 81:195-206. https://doi. org/10.1785/gssrl.81.2.195

Aksu AE, Hall J, Yaltirak C (2005) Miocene to Recent tectonic evolution of the eastern Mediterranean: new pieces of the old Mediterranean puzzle. Mar Geol 221:1-13

Aliaj S (1998) Neotectonic structure of Albania. Albanian J Nat Tech Sci 4:79-97

Aliaj S (1999) Transverse faults in Albanian orogen front. Albanian J Nat Tech Sci 6:121-132

Aliaj S (2000) Neotectonics and seismicity in Albania. In: Meco S, Aliaj S, Turku I (eds) Geology of Albania. Gebruder Borntrager, Berlin. Beitrage zur regionalen Geologie der Erde 28:135-178

Aliaj S (2002) Seismotectonic model used for hazard calculations of Albania according to OHAZ computer code. Archive of Seismological Institute, Tirana, Albania

Aliaj S (2006) The Albanian orogen: convergence zone between Eurasia and the Adria microplate. In: Pinter N, Gyula G, Weber J, Stein S, Medak D (eds) The Adria microplate: GPS geodesy, tectonics and hazards. Nato Science Series: IV: Earth and Environmental Sciences, 61. Springer, Dordrecht

Aliaj S, Sulstarova E, Muço B, Koçiu S (2000) Seismotectonic map of Albania, scale 1:500,000. Seismological Institute, Tirana

Aliaj S, Adams J, Halchuk S, Sulstarova E, Peci V, Muco B (2004) Probabilistic seismic hazard maps for Albania. In: 13th world conference on earthquake engineering, Vancouver, Canada, August 1-6 2004, paper no 2469

Ambraseys NN (1995) The prediction of earthquake peak ground acceleration in Europe. Earthq Eng Struct Dyn 24:467-490

Anderson JG, Luco JE (1983) Consequences of slip rate constants on earthquake occurrence relations. Bull Seismol Soc Am 73:471-496

Argnani A (2013) The influence of Mesozoic palaeogeography on the variations in structural style along the front of the Albanide thrust-and-fold belt. It J Geosci 132(2):175-185

Argnani A, Frugoni F, Cosi R, Ligi M, Favali P (2001) Tectonics and seismicity of the Apulian Ridge south of Salento peninsula (Southern Italy). Ann Geofis 44:527-540

AUTH (Aristotle University of Thessaloniki, Department of Geophysics) (2012) Monthly bulletins, http:// geophysics.geo.auth.gr/the_seisnet/WEBSITE_2005/bulletins_en.html

Baba AB, Papadimitriou EE, Papazachos BC, Papaioannou ChA, Karakostas BG (2000) Unified local magnitude scale for earthquakes of south Balkan area. Pure Appl Geophys 157:765-783

Bakun WH, Aagaard B, Dost B, Ellsworth WL, Hardebeck JL, Harris RA, Ji C, Johnston MJS, Langbein J, Lienkaemper JJ, Michael AJ, Murray JR, Nadeau RM, Reasenberg PA, Reichle MS, Roeloffs EA, Shakal A, Simpson RW, Waldhauser F (2005) Implications for prediction and hazard assessment from the 2004 Parkfield earthquake. Nature 437:969-974

Basili R, Valensise G, Vannoli P, Burrato P, Fracassi U, Mariano S, Tiberti MM (2008) The database of individual seismogenic sources (DISS), version 3: summarizing 20 years of research on Italy's earthquake geology. Tectonophysics 453:20-43. https://doi.org/10.1016/j.tecto.2007.04.014

Basili R, Kastelic V, Demircioglu MB, Garcia Moreno D, Nemser ES, Petricca P, Sboras SP, BesanaOstman GM, Cabral J, Camelbeeck T, Caputo R, Danciu L, Domac H, Fonseca J, García-Mayordomo J, Giardini D, Glavatovic B, Gulen L, Ince Y, Pavlides S, Sesetyan K, Tarabusi G, Tiberti MM, Utkucu M, Valensise G, Vanneste K, Vilanova S , Wössner J (2013) The European Database of Seismogenic Faults (EDSF) compiled in the framework of the Project SHARE. http://diss.rm. ingv.it/share-edsf/, https://doi.org/10.6092/INGV.IT-SHARE-EDSF

Bragato PL, Slejko D (2005) Empirical ground motion attenuation relations for the eastern Alps in the magnitude range 2.5-6.3. Bull Seismol Soc Am 95:252-276

Bragato PL, Sugan M, Augliera P, Massa M, Vuan A, Saraò A (2011) Moho reflection effects in the Po Plain (northern Italy) observed from instrumental and intensity data. Bull Seismol Soc Am 101:2142-2152

Bungum H (2007) Numerical modelling of fault activities. Comput Geosci 33:808-820

Caputo R, Pavlides S (2013) The Greek Database of Seismogenic Sources (GreDaSS), version 2.0.0: A compilation of potential seismogenic sources $(\mathrm{Mw}>5.5)$ in the Aegean Region. http://gredass. unife.it/, https://doi.org/10.15160/unife/gredass/0200 
Caputo R, Chatzipetros A, Pavlides S, Sboras S (2012) The Greek Database of Seismogenic Sources (GreDaSS): state-of-the-art for northern Greece. Ann Geophys 55(5):859-894. https://doi.org/10. 4401/ag-5168

Casero P, Roure F, Edignoux L, Moretti I, Muller C, Sage L, Vially R (1988) Neogene geodynamic evolution of the Southern Apennines. Memorie Soci Geol It 41:109-125

Cavazza W, Wezel FC (2003) The Mediterranean region - a geological primer. Episodes 26(3):160-168

CEN (European Committee for Standardisation) (2005) Eurocode 8: Design of structures for earthquake resistance. Part 1: General rules, Seismic action and rules for buildings. EN 1998-1, European Union Per Regulation, Brussels, Belgium

CEN (European Committee for Standardization) (2006) Eurocode 8: Design of structures for earthquake resistance. Part 4: Silos, tanks and pipelines. EN 1998-4, European Union Per Regulation, Brussels, Belgium

Chen WW, Shih B, Chen Y-C, Hung J-H, Hwang HH (2002) Seismic response of natural gas and water pipelines in the Ji-Ji earthquake. Soil Dyn Earthq Eng 22:1209-1214. https://doi.org/10.1016/ S0267-7261(02)00149-5

Coppersmith KJ, Youngs RR (1986) Capturing uncertainty in probabilistic seismic hazard assessments within intraplate environments. In: Proceedings of the 3rd National Conference on Earthquake Engineering, vol. 1, pp 301-312

Cornell CA (1968) Engineering seismic risk analysis. Bull Seismol Soc Am 58:1583-1606

Cotton F, Scherbaum F, Bommer JJ, Bungum H (2006) Criteria for selecting and adjusting ground-motion models for specific target regions: application to Central Europe and rock sites. J Seismol 10:137156. https://doi.org/10.1007/s10950-005-9006-7C

Danciu L, Tselentis G-A (2007) Engineering ground-motion parameters attenuation relationships for Greece. Bull Seismol Soc Am 97:162-183

D'Argenio B, Pescatore T, Scandone P (1973) Schema geologico dell'Appennino meridionale (Campania e Lucania). Atti Accademia Nazionale dei Lincei 183:49-72

De Risi R, De Luca F, Kwon O-S, Sextos A (2018) Scenario-based seismic risk assessment for buried transmission gas pipelines at regional scale. J Pipeline Syst Eng Pract 9(4):04018018

Dilek Y, Pavlides S (eds) (2006) Post-collisional tectonics and magmatism in the Mediterranean and Asia. Geological Society of America, Special Papers, 409. https://doi.org/10.1130/SPE409

D'Ingeo F, Calcagnile G, Panza GF (1980) On the fault-plane solutions in the central-eastern Mediterranean region. Boll Geof Teor Appl 22:13-22

Douglas J (2011) Ground-motion prediction equations 1964-2010. PEER Report 2011/102, Pacific Earthquake Engineering Research Center, College of Engineering, Berkeley, CA, ISSN 1547-0587X

Dumurdzanov N, Serafimovski T, Burchfiel C (2005) Cenozoic tectonics of Macedonia and its relation to the South Balkan extensional regime. Geosphere 1(1):1-22

Duni L, Kuka Sh, Kuka N (2010) Local relations for converting ML to MW in southern-western Balkan region. Acta Geod Geoph Hung 45(3):317-323

Engdahl ER, Villaseñor A (2002) Global Seismicity, 1900-1999. In: Lee WHK, Kanamori H, Jennings PC, Kisslinger C (eds) International Handbook of Earthquake and Engineering Seismology, Part A, chapter 41, Academic Press, pp 665-690

Esposito S, Giovinazzi S, Elefante L, Iervolino I (2009) Performance of the L'Aquila (central Italy) gas distribution network in the 2009 (MW 6.3) earthquake. Bull Earthq Eng 11:2447-2466. https://doi.org/ 10.1007/s10518-013-9478-8

Faccenna C, Becker TW, Auer L, Billi A, Boschi L, Brun JP, Capitanio FA, Funiciello F, Horvàth F, Jolivet L, Piromallo C, Royden L, Rossetti F, Serpelloni E (2014) Mantle dynamics in the Mediterranean. Rev Geophys 52(3):283-332. https://doi.org/10.1002/2013RG000444

Favali P, Mele G, Mattietti G (1990) Contribution to the study of the Apulian microplate geodynamics. Mem Soc Geol It 44:71-80

Finetti IR (2005) CROP Project: deep seismic exploration of the Central Mediterranean and Italy. Elsevier, Amsterdam

Finetti IR, Del Ben A (2005) Crustal tectono-stratigraphic setting of the Adriatic Sea from new CROP seismic data. In: Finetti IR (ed) CROP, deep seismic exploration of the mediterranean region. Elsevier, Amsterdam, pp 519-547

Frasheri A, Bushati S, Bare V (2009) Geophysical outlook on structure of the Albanides. J Balkan Geophys Soc 12(1):9-30

Galli P, Naso G (2008) The "taranta" effect of the 1743 earthquake in Salento (Apulia, southern Italy). Boll Geof Teor Appl 49(2):177-204

Gardner JK, Knopoff L (1974) Is the sequence of earthquakes in southern California, with aftershocks removed, Poissonian? Bull Seismol Soc Am 64:1363-1367 
Gasparini C, Iannaccone G, Scarpa R (1985) Fault-plane solutions and seismicity of the Italian peninsula. Tectonophysics 117:59-79

GCMT (Global Centroid Moment Tensor Catalogue) (2012) http://www.globalcmt.org/CMTsearch.html

Giardini D, Woessner J, Danciu L (2014) Mapping Europe's Seismic Hazard. Eos 95(29):261-262

Golara A (2014) Probabilistic seismic hazard analysis of interconnected infrastructure: a case of Iranian high-pressure gas supply system. Nat Hazards 73:567-657. https://doi.org/10.1007/ s11069-014-1087-6

Grant LB (1996) Uncharacteristic earthquakes on the San Andreas Fault. Science 272:826-827

Gruppo di Lavoro CPTI (2004) Catalogo Parametrico dei Terremoti Italiani, versione 2004 (CPTI04). INGV, Bologna. http://emidius.mi.ingv.it/CPTI/

Gueguen E, Doglioni C, Fernandez M (1998) On the post-25 Ma geodynamic evolution of the western Mediterranean. Tectonophysics 298:259-269

Hollenstein C, Geiger A, Kahle HG, Veis G (2006) CGPS time-series and trajectories of crustal motion along the West Hellenic Arc. Geophys J Int 164(1):182-191. https://doi.org/10.1111/j.1365-246X. 2005.02804.x

IAEA (2010) Seismic hazards in site evaluation for nuclear installations. IAEA, Vienna

IAEA (2015) The Contribution of palaeoseismology to seismic hazard assessment in site evaluation for nuclear installations. IAEA-TECDOC-1767, International Atomic Energy Agency, Vienna, ISBN 978-92-0-105415-9, ISSN 1011-4289

ISC (International Seismological Centre) (2012) On-line Bulletin. Internat. Seis. Centre, Thatcham, United Kingdom. http://www.isc.ac.uk/Bull

ISIDe Working Group (2007) Italian Seismological Instrumental and Parametric Database (ISIDe). Istituto Nazionale di Geofisica e Vulcanologia (INGV). https://doi.org/https://doi.org/10.13127/ISIDE

Jardin A, Roure F, Nikolla L (2011) Subsalt depth seismic imaging and structural interpretation in Dumre area, Albania. Oil Gas Sci Technol 66:911-929

Jimenez MJ, Giardini D, Gruenthal G, the SESAME Working Group (Erdik M, Garcia-Fernandez J, Lapajne J, Makropoulos K, Musson R, Papaioannou Ch, Rebez A, Riad S, Sellami S, Shapira A, Slejko D, van Eck T, El Sayed A) (2001) Unified seismic hazard modelling throughout the Mediterranean region. Boll Geof Teor App 42:3-18

Jolivet L, Brun JP (2010) Cenozoic geodynamic evolution of the Aegean. Int J Earth Sciences 99:109-138

Jouanne F, Mugnier JL, Koci R, Bushati S, Matev K, Kuka N, Shinko I, Kociu S, Duni L (2012) GPS constraints on current tectonics of Albania. Tectonophysics 554-557:50-62

Joyner WB, Boore DM (1981) Peak horizontal acceleration and velocity from strong-motion records including records from the 1979 Imperial Valley, California, earthquake. Bull Seismol Soc Am 71:2011-2038

Kanamori H, Anderson DL (1975) Theoretical basis of some empirical relations in seismology. Bull Seismol Soc Am 65:1073-1095

Karnik V (1996) Seismicity of Europe and the Mediterranean. Academy of Sciences of the Czech Republic, Geophysical Institute, plus earthquake catalogue

Kijko A, Graham G (1998) Parametric historic procedure for probabilistic seismic hazard analysis. Part 1: Estimation of maximum regional magnitude. Pure Appl Geophys 152(3):413-442

Kijko A, Sellevoll MA (1989) Estimation of earthquake hazard parameters from incomplete data files, Part I, Utilization of extreme and complete catalogues with different threshold magnitudes. Bull Seismol Soc Am 79:645-654

Kilias A, Thomaidou E, Katrivanos E, Vamvaka A, Fassoulas C, Pipera K, Falalakis G, Avgerinas S, Sfeikos A (2016) A geological cross-section through northern Greece from Pindos to Rhodope Mountain Ranges: a field guide across the External and Internal Hellenides. In: Kilias A, Lozios S (ed), Geological field trips in the Hellenides. Journal of the Virtual Explorer, Electronic Edition, vol 50, paper 1. https://doi.org/10.3809/jvirtex.2016.08685

Kulkarni RB, Youngs RR, Coppersmith, KJ (1984) Assessment of confidence intervals for results of seismic hazard analysis. In: Proceedings of the eighth world conference on earthquake engineering, San Francisco, July 21-28, 1984

Lacombe O, Malandain J, Vilasi N, Amrouch K, Roure F (2009) From paleostress to paleoburial in foldthrust belts: Preliminary results from calcite twin analysis in the Outer Albanides. Tectonophysics 475:128-141

Latoussakis J, Stavrakakis GN (1992) Times of increased probability of earthquakes of ML $\geq 5.5$ in Greece diagnosed by algorithm M8. Tectonophysics 210:315-326

Le Pichon X, Kreemer C (2010) Kinematic evolution of the Eastern Mediterranean and Middle East and its implications for dynamics. Annu Rev Earth Planet Sci 38(1):323-351. https://doi.org/10.1146/annur ev-earth-040809-152419 
Liu A, Chen K, Wu J (2010) State of art of seismic design and seismic hazard analysis for oil and gas pipeline system. Earthq Sci 23:259-263. https://doi.org/10.1007/s11589-010-0721-y

Maesano FE, Volpi V, Civile D, Basili R, Conti A, Tiberti MM, Accettella D, Conte R, Zgur F, Rossi G (2020) Active extension in a foreland trapped between two contractional chains: The South Apulia Fault System (SAFS). Tectonics 39:e2020TC006116. https://doi.org/10.1029/2020TC006116

Makropoulos K, Kaviris G, Kouskouna V (2012) An updated and extended earthquake catalogue for Greece and adjacent areas since 1900. Nat Hazards Earth Syst Sci 12:1425-1430

Mangano G, Zecchin M, Civile D (2020) Large-scale gravity-driven phenomena in the Crotone Basin, southern Italy. Mar Pet Geol 117:104386

McClusky S, Reilinger R, Mahmoud S, Ben-Sari D, Tealeb A (2003) GPS constraints on Africa (Nubia) and Arabia plate motions. Geophys J Int 155:126-138

McGuire RK (1977) Effects of uncertainties in seismicity on estimates of seismic hazard for the east coast of the United States. Bull Seismol Soc Am 67:827-848

McGuire RK (1995) Probabilistic seismic hazard analysis and design earthquakes: closing the loop. Bull Seismol Soc Am 85:1275-1284

McGuire RK (2001) Deterministic vs. probabilistic earthquake hazards and risks. Soil Dyn Earthq Eng $21: 377-384$

McGuire RK (2004) Seismic hazard and risk analysis. EERI Monograph MNO-10, Earthquake Engineering Research Institute, Oakland, California

McGuire RK, Shedlock KM (1981) Statistical uncertainties in seismic hazard evaluations in the United States. Bull Seismol Soc Am 71:1287-1308

Meletti C, Galadini F, Valensise G, Stucchi M, Basili R, Barba S, Vannucci G, Boschi E (2008) A seismic source zone model for the seismic hazard assessment of the Italian territory. Tectonophysics 450:85-108

Meinhold G, Kostopoulos DK (2013) The Circum-Rhodope Belt, northern Greece: age, provenance, and tectonic setting. Tectonophysics 595-596:55-68

Melissianos VE, Vamvatsikos D, Gantes CJ (2017) Performance assessment of buried pipelines at fault crossings. Earthq Spectra 33:201-218

Menant A, Jolivet L, Vrielynck B (2016) Kinematic reconstructions and magmatic evolution illuminating crustal and mantle dynamics of the eastern Mediterranean region since the late Cretaceous. Tectonophysics 675:103-140

Milia A, Iannace P, Torrente MM (2017) Active tectonic structures and submarine landslides offshore southern Apulia (Italy): A new scenario for the 1743 earthquake and subsequent tsunami. Geo-Mar Lett 37(3):229-239. https://doi.org/10.1007/s00367-017-0493-7

Molinari I, Morelli A (2011) EPcrust: A reference crustal model for the European plate. Geophys J Int 185(1):352-364. https://doi.org/10.1111/j.1365-246X.2011.04940.x

Moratto L, Vuan A, Saraò A, Slejko D, Bragato P, Caputo R, Ceramicola S, Chatzipetros A, Civile D, Daja S, Fabris P, Garcia J, Geletti R, Papazachos C, Pavlides S, Rapti D, Rebez A, Rossi G, Sandron D, Santulin M, Sboras S, Tamaro A, Volpi V, Zecchin M, Zgur F, Zuliani D (2020) Seismic hazard assessment for the trans adriatic pipeline (TAP) (Part2): broadband scenarios at Fier Compressor Station (Albania). Bull Earth Eng. https://doi.org/10.1007/s10518-021-01122-z

Moretti I, Royden L (1988) Deflection, gravity anomalies and tectonics of doubly subducted continental lithosphere: Adriatic and Ionian Seas. Tectonics 7(4):875-893

Mostardini F, Merlini S (1986) Appennino centro-meridionale. Sezioni geologiche e proposta di modello strutturale. Memorie Soc Geol It 35:177-202

Mountrakis DM (2010) Geology and geotectonic evolution of Greece. University Studio Press, Tirana

Mountrakis D, Sapountzis E, Kilias A, Eleftheriadis G, Christofides G (1983) Paleogeographic conditions in the western Pelagonian margin in Greece during the initial rifting of the continental area. Can J Earth Sci 20:1673-1681

Mousavi M, Hesari M, Azarbakht A (2014) Seismic risk assessment of 3rd Azerbaijan gas pipeline in Iran. Nat Hazards 74:1327-1348. https://doi.org/10.1007/s11069-014-1244-y

NEIC (National Earthquake Information Center) (2012) Earthquake Hazards Program. http://neic.usgs.gov/ neis/epic/index.html

Nicol A, Walsh JJ, Manzocchi T, Morewood N (2005) Displacement rates and average earthquake recurrence intervals on normal faults. J Struct Geol 27:541-551. https://doi.org/10.1016/j.jsg.2004.10.009

Nieuwland D, Oudmayer BC, Valbona U (2001) The tectonic development of Albania: explanation and prediction of structural style. Mar Pet Geol 18:161-177

NOA (National Observatory of Athens, Institute of Geodynamics) (2012) Earthquake catalogues. http:// www.gein.noa.gr/en/seismicity/earthquake-catalogs 
Nocquet JM (2012) Present-day kinematics of the Mediterranean: a comprehensive overview of GPS results. Tectonophysics 579:220-242

O'Rourke MJ (2009) Wave propagation damage to continuous pipe. In: Proceedings of the Tech. Counc. Lifeline Earthq. Eng. Conf. (TCLEE), Oakland, CA, June 28-July 1. https://doi.org/10.1061/41050 (357)76

O'Rourke TD, Palmer MC (1996) Earthquake performance of gas transmission pipelines. Earthq Spectra 12:493-527

Ordaz M, Martinelli F, D’Amico V, Meletti C (2013) CRISIS2008: a flexible tool to perform probabilistic seismic hazard assessment. Seismol Res Lett 84:495-504. https://doi.org/10.1785/0220120067

Orozova-Stanishkova I, Slejko D (1994) Seismic hazard of Bulgaria. Nat Hazards 9:247-271

Pacheco JF, Sykes LR (1992) Seismic moment catalog of large shallow earthquakes, 1900 to 1989. Bull Seismol Soc Am 82:1306-1349

Papageorgiou AS, Aki K (1983) A specific barrier model for the quantitative description of inhomogeneous faulting and the prediction of strong ground motion. Bull Seismol Soc Am 73:693-722

Papaioannou Ch, Papazachos BC (2000) Time-independent and time-dependent seismic hazard in Greece based on seismogenic sources. Bull Seismol Soc Am 90:22-33

Papazachos BC, Papazachou CB (2003) The earthquakes of Greece. Ziti Publications, Thessaloniki (in Greek)

Papazachos BC, Papadimitriou EE, Karakaisis GF, Panagiotopoulos DG (1997) Long-term earthquake prediction in the circum-Pacific convergent belt. Pure Appl Geophys 149:173-217

Papazachos CB (2019) Deep structure and active tectonics of the South Aegean volcanic arc. Elements 15:153-158

Papazachos CB, Papaioannou C (1997) The macroseismic field in the Balkan area. J Seismol 1:181-201

Papanikolaou DJ (1997) The tectonostratigraphic terranes of the Hellenides. Ann Géol Pays Hellén 37:495-514

Papanikolaou D (2009) Timing of tectonic emplacement of the ophiolites and terrane paleogeography in the Hellenides. Lithos 108:262-280

Patacca E, Scandone P (2001) Late thrust propagation and sedimentary response in the thrust belt-foredeep system of the southern Apennines (Pliocene-Pleistocene). In: Vai GB, Martini IP (eds) Anatomy of an Orogen: the Apennines and Adjacent Mediterranean Basins. Kluwer, Dordrecht, pp 401-440

Patacca E, Scandone P (2007) Geology of Southern Apennines. In: Mazzotti A, Patacca E, Scandone P (eds), Results of the CROP Project Sub-project CROP-04 Southern Apennines (Italy). Boll Soc Geol It (Italian Journal of Geoscience) special issue 7:75-119

Pavlides S, Caputo R, Sboras S, Chatzipetros A, Papathanasiou G, Valkaniotis S (2010) The Greek catalogue of active faults and database of seismogenic sources. Bull Geol Soc Greece 43(1):486-494

Pérouse E, Chamot-Rooke N, Rabaute A, Briole P, Jouanne F, Georgiev I, Dimitrov D (2012) Bridging onshore and offshore present-day kinematics of central and eastern Mediterranean: implications for crustal dynamics and mantle flow. G3 13:Q09013. https://doi.org/10.1029/2012GC004289

Pyrras NK, Sextos AG (2018) Safety of buried steel natural gas pipelines under earthquake-induced ground shaking: a review. Soil Dyn Earthq Eng 106:254-277

Robertson A, Shallo M (2000) Mesozoic-Tertiary tectonic evolution of Albania in its region eastern Mediterranean context. Tectonophysics 316:197-254

Rossi G, Caputo R, Zuliani D, Fabris P, Maggini M, Karvelis P (2020) Analysis of global navigation satellite system data along the Southern Gas Corridor and estimate of the expected displacement. Environ Geosci 27:117-141. https://doi.org/10.1306/eg.01222019023

Roure F, Nazaj S, Fili I, Cadet JP, Mushka K, Bonneau M (2004) Kinematic evolution and petroleum systems-an appraisal of the Outer Albanides. AAPG Mem 82:474-493

Rovida A, Camassi R, Gasperini P, Stucchi M (a cura di) (2011) CPTI11, la versione 2011 del Catalogo Parametrico dei Terremoti Italiani. Milano, Bologna. http://emidius.mi.ingv.it/CPTI

Sakurai A, Takanashi T (1969) Dynamic stresses of underground pipelines during earthquakes. In: Proceedings of the 4th world conference Earthq Engng, Santiago, Chile, 1969, p 81

Salic RB, Milutinovic ZV, Garevski MA (2010) The needs for advanced seismic hazard assessment of the Republic of Macedonia. In: ECEE (ed), Proceedings of the 14th ECEE, Ohrid, 30/8-3/9, 2010, CD-Rom

Sandron D, Santulin M, Tamaro A, Orci C, Benedetti G, Castellaro S, Romeo R, Rebez A, Grimaz S, Malisan P, Guadagnini G, Sciascia F, Slejko D (2019) Seismic parameter design assessment for the Kribi deep seaport in Cameroon. Bull Earthq Eng 17:1825-1861. https://doi.org/10.1007/ s10518-018-0518-2

Schwartz DP, Coppersmith KJ (1984) Fault behavior and characteristic earthquakes: examples from the Wasatch and San Andreas fault zones. J Geophys Res 89:5681-5698 
Scordilis EM (2005) Globally valid relations converting Ms, mb and MJMA to Mw. In: NATO advanced research workshop on earthquake monitoring and seismic hazard mitigation in Balkan Countries, 11-17 September 2005, the Rila Mountains-Resort Village Borovetz, Bulgaria, Abstracts book, pp $158-161$

Scordilis EM (2006) Empirical global relations converting Ms and $\mathrm{mb}$ to moment magnitude. J Seismol 10:225-236. https://doi.org/10.1007/s10950-006-9012-4

SEAHELLARC Working Group (Slejko D, Santulin M, Garcia J, Papoulia J, Daskalaki E, Fasulaka Ch, Fokaefs A, Ilinski D, Mascle J, Makris J, Nicolich R, Papadopoulos G, Tsambas A, Wardell N) (2010) Preliminary seismic hazard assessment for the area of Pylos and surrounding region (SW Peloponnese). Boll Geof Teor Appl 50:163-186

SEAHELLARC Working Group (Papoulia J, Nicolich R, Makris J, Slejko D, Mascle J, Papadopoulos G, Anagnostou Ch, Camera L, Daskalaki E, Fasoulaka Ch, Fokaefs A, Fountoulis I, Garcia J, Gulkan P, Mariolakos I, Pomonis A, Santulin M, Tsambas A, Wardell N, Yalçiner A) (2014) A new seismogenic model for the Kyparissiakos Gulf and western Peloponnese (SW Hellenic Arc). Boll Geof Teor Appl 55:405-432. https://doi.org/10.4430/bgta0127

Shebalin NV, Karnik V, Hadzievski D (eds) (1974) Catalogue of earthquakes, part I, 1901-1970; part II, prior to 1901. UNDP Unesco Survey of the Seismicity of the Balkan Region, Unesco, Skopje

Shebalin NV, Leydecker G, Mokrushina NG, Tatevossian RE, Erteleva OO, Vassiliev V Yu (1998) Earthquake Catalogue for Central and Southeastern Europe 342 BC-1990 AD-Final Report to Contract ETNU-CT 93-0087

Shiner P, Beccacini A, Mazzoli S (2004) Thin-skinned versus thick skinned structural models for Apulian carbonate reservoirs: constraints from the Val d'Agri Fields, S Apennines, Italy. Mar Pet Geol 21:805-827

Silo V, Nishani P, Silo E (2010) Hydrocarbon exploration under Kruja zone in Tirana-Rodon area, Albania. J Balkan Geophys Soc 13(1):9-16

Simeonova SD, Solakov DE, Leydecker G, Busche H, Schmitt T, Kaiser D (2006) Probabilistic seismic hazard map for Bulgaria as a basis for a new building code. Nat Hazards Earth Syst Sci 6:881-887

Slejko D, Peruzza L, Rebez A (1998) Seismic hazard maps of Italy. Ann Geofis 41(2):183-214

Slejko D, Camassi R, Cecic I, Herak D, Herak M, Kociu S, Kouskouna V, Lapajne J, Makropoulos K, Meletti C, Muco B, Papaioannou C, Peruzza L, Rebez A, Scandone P, Sulstarova E, Voulgaris N, Zivcic M, Zupancic P (1999) Seismic hazard assessment for Adria. Ann Geofis 42:1085-1107

Slejko D, Carulli GB, Garcia J, Santulin M (2011) The contribution of "silent" faults to the seismic hazard of the northern Adriatic Sea. J Geodyn 51:166-178. https://doi.org/10.1016/j.jog.2010.04.009

Slejko D, Santulin M, Garcia J (2014) Seismic hazard estimates for the area of Pylos and surrounding region (SW Peloponnese) for seismic and tsunami risk assessment. Boll Geof Teor Appl 55:433468. https://doi.org/10.4430/bgta0090

Stepp JC (1972) Analysis of completeness of the earthquake sample in the Puget Sound area and its effect on statistical estimates of earthquake hazard. In: Proceedings of the international conference on microzonation, vol 2, pp 897-910

Stucchi M, Meletti C, Montaldo V, Crowley H, Calvi GM, Boschi E (2011) Seismic hazard assessment (2003-2009) for the Italian building code. Bull Seismol Soc Am 101:1885-1911. https://doi.org/ $10.1785 / 0120100130$

Stucchi M, Rovida A, Gomez Capera AA, Alexandre P, Camelbeeck T, Demircioglu MB, Gasperini P, Kouskouna V, Musson RMW, Radulian M, Sesetyan K, Vilanova S, Baumont D, Bungum H, Fäh D, Lenhardt W, Makropoulos K, MartinezSolares JM, Scotti O, Živčić M, Albini P, Batllo J, Papaioannou C, Tatevossian R, Locati M, Meletti C, Viganò D, Giardini D (2012) The SHARE European Earthquake Catalogue (SHEEC) 1000-1899. J Seismol. https://doi.org/10.1007/ s10950-012-9335-2

Sulstarova E, Aliaj Sh (2001) Seismic hazard assessment in Albania. Albania J Nat Tech Sci 10:89-100

Swan FH III, Schwartz DP, Cluff LS (1980) Recurrence of moderate-to-large magnitude earthquakes produced by surface faulting on the Wasatch fault zone. Bull Seismol Soc Am 70:1431-1462

TAP AG (2020) Trans Adriatic Pipeline. https://www.tap-ag.com

Taymaz T, Jackson JA, Westaway R (1990) Earthquake mechanisms in the Hellenic Trench near Crete. Geophys J Int 102:695-731

Taymaz T, Yilmaz Y, Dilek Y (2007) The geodynamics of the Aegean and Anatolia: introduction. Geological Society, London, Special Publications 291:1-16. https://doi.org/10.1144/SP291.1

Toro GR, Abrahamson NA, Schneider JF (1997) Model of strong motions from earthquakes in central and eastern North America: best estimates and uncertainties. Seism Res Lett 68:41-57

Tsampas, A (2006) The critical earthquake model in low seismicity areas of Europe. MSc Thesis, Aristotle University of Thessaloniki (in Greek) 
Utsu $\mathrm{T}$ (1965) A method for determining the value of $\mathrm{b}$ in the formula $\log \mathrm{N}=\mathrm{a}-\mathrm{bM}$ showing the magnitude-frequency relation for earthquakes. Geophys Bull Hokkaido Univ 13:99-103

Vamvakaris DA, Papazachos CB, Papaioannou CA, Scordilis EM, Karakaisis GF (2016) A detailed seismic zonation model for shallow earthquakes in the broader Aegean area. Nat Hazard 16:55-84

Van Hinsbergen DJJ, Schmid SM (2012) Map-view restoration of Aegean-west Anatolian accretion and extension since the Eocene. Tectonics 31:TC5005. https://doi.org/10.1029/2012TC003132

Velaj T, Davison I, Serjani A, Alsop I (1999) Thrust tectonics and the role of evaporates in the Ionian Zone of the Albanides. AAPG Bull 83(9):1408-1425

Vilasi N, Malandain J, Barrier L, Callot J-P, Amrouch K, Guilhaumou N, Lacombe O, Muska K, Roure F, Swennen R (2009) From outcrop and petrographic studies to basin-scale fluid flow modelling: the use of the Albanian natural laboratory for carbonate reservoir characterization. Tectonophysics 474(1-2):367-392. https://doi.org/10.1016/j.tecto.2009.01.033

Wallace RE (ed) (1986) Impacts on society, Active Tectonics. National Academy Press, Washington, DC

Weichert DH (1980) Estimation of the earthquake recurrence parameters for unequal observation periods for different magnitudes. Bull Seismol Soc Am 70:1337-1346

Wells DL, Coppersmith KJ (1994) New empirical relationships among magnitude, rupture length, rupture width, rupture area, and surface displacement. Bull Seismol Soc Am 84:974-1002

Wesnousky SG (1986) Earthquakes, quaternary faults, and seismic hazard in California. J Geophys Res 91:12587-12631

Wesnousky SG (1994) The Gutenberg-Richter or characteristic earthquake distribution, which is it? Bull Seismol Soc Am 84(6):1940-1959

Youngs RR, Coppersmith KJ (1985) Implications of fault slip rates and earthquake recurrence models to probabilistic seismic hazard assessments. Bull Seismol Soc Am 75:939-964

Zecchin M, Accaino F, Ceramicola S, Civile D, Critelli S, Da Lio C, Mangano G, Prosser G, Teatini P, Tosi L (2018) The Crotone Megalandslide, southern Italy: architcture, timing and tectonic control. Sci Rep 8(1):77-78. https://doi.org/10.1038/s41598-018-26266-y

Zelilidis A, Piper DJW, Vakalas I, Avramidis P, Getsos K (2003) Oil and gas plays in Albania: do equivalent plays exist in Greece? J Pet Geol 26(1):29-48

Publisher's Note Springer Nature remains neutral with regard to jurisdictional claims in published maps and institutional affiliations. 